\title{
An Overview of Several Inhibitors for Alzheimer's Disease: Characterization and Failure
}

\author{
Subramanian Boopathi ${ }^{1}$, Adolfo B. Poma ${ }^{2,3}$ and Ramón Garduño-Juárez 1,*(D) \\ 1 Instituto de Ciencias Físicas, Universidad Nacional Autónoma de México, Cuernavaca 62210, Mexico; \\ boopathi@icf.unam.mx \\ 2 Department of Biosystems and Soft Matter, Institute of Fundamental Technological Research Polish Academy \\ of Science, Pawińskiego 5B, 02-106 Warsaw, Poland \\ 3 International Center for Research on Innovative Biobased Materials (ICRI-BioM) - International Research \\ Agenda, Lodz University of Technology, Zeromskiego 116, 90-924 Lodz, Poland; \\ adolfo.poma-bernaola@p.lodz.pl \\ * Correspondence: ramon@icf.unam.mx
}

check for

updates

Citation: Boopathi, S.; Poma, A.B.; Garduño-Juárez, R. An Overview of Several Inhibitors for Alzheimer's Disease: Characterization and Failure. Int. J. Mol. Sci. 2021, 22, 10798. https://doi.org/10.3390/ ijms221910798

Received: 28 August 2021

Accepted: 3 October 2021

Published: 6 October 2021

Publisher's Note: MDPI stays neutral with regard to jurisdictional claims in published maps and institutional affiliations.

Copyright: (c) 2021 by the authors. Licensee MDPI, Basel, Switzerland. This article is an open access article distributed under the terms and conditions of the Creative Commons Attribution (CC BY) license (https:/ / creativecommons.org/licenses/by/ $4.0 /)$.

\begin{abstract}
Amyloid beta $(A \beta)$ oligomers are the most neurotoxic aggregates causing neuronal death and cognitive damage. A detailed elucidation of the aggregation pathways from oligomers to fibril formation is crucial to develop therapeutic strategies for Alzheimer's disease (AD). Although experimental techniques rely on the measure of time- and space-average properties, they face severe difficulties in the investigation of $\mathrm{A} \beta$ peptide aggregation due to their intrinsically disorder character. Computer simulation is a tool that allows tracing the molecular motion of molecules; hence it complements $A \beta$ experiments, as it allows to explore the binding mechanism between metal ions and $\mathrm{A} \beta$ oligomers close to the cellular membrane at the atomic resolution. In this context, integrated studies of experiments and computer simulations can assist in mapping the complete pathways of aggregation and toxicity of $A \beta$ peptides. $A \beta$ oligomers are disordered proteins, and due to a rapid exploration of their intrinsic conformational space in real-time, they are challenging therapeutic targets. Therefore, no good drug candidate could have been identified for clinical use. Our previous investigations identified two small molecules, M30 (2-Octahydroisoquinolin-2(1H)-ylethanamine) and gabapentin, capable of $\mathrm{A} \beta$ binding and inhibiting molecular aggregation, synaptotoxicity, intracellular calcium signaling, cellular toxicity and memory losses induced by $A \beta$. Thus, we recommend these molecules as novel candidates to assist anti-AD drug discovery in the near future. This review discusses the most recent research investigations about the $A \beta$ dynamics in water, close contact with cell membranes, and several therapeutic strategies to remove plaque formation.
\end{abstract}

Keywords: Alzheimer's disease; amyloid $\beta$ peptide; plaque formation; small molecules; M30; gabapentin; MD simulation

\section{Introduction}

Approximately 50 million people are globally affected by Alzheimer's disease (AD) [1,2]. This number will increase to 150 million by 2050 unless new prevention treatments become available [1]. Amyloid plaques and neurofibrillary tangles in brain tissue are the main hallmarks of AD. Amyloid plaques are composed of amyloid $\beta(\mathrm{A} \beta)$ peptides. Neurofibrillary tangles are composed of hyperphosphorylated tau proteins. In 1992, Hardy and Higgins [2] developed the amyloid cascade hypothesis; $\mathrm{A} \beta$ aggregates are transformed into $\mathrm{A} \beta$ fibrils that accumulate in the brain and finally trigger neurodegeneration.

Amyloid precursor protein (APP) gene generates three variant APP695, APP751 and APP770, which are produced in neurons, endothelial cells, and platelets, respectively. In the aggregation pathway, transmembrane APP695 is cleaved by $\beta$ - and $\gamma$-secretase to generates $\mathrm{A} \beta_{1-40}$ and $\mathrm{A} \beta_{1-42}$ peptides. During the APP695 cleavage, two processes occur (Figure 1 ). (1) $A \beta$ is released to the extracellular hydrophobic environment, where $A \beta$ monomers 
assemble into dimers, trimers, tetramers, oligomers, and fibrils [3-6], A $\beta$ fibrils constitute the amyloid plaques considered a major pathological hallmark of AD. (2) A small amount of $A \beta$ remains above the cellular membrane and can form membrane-associated $A \beta$ oligomers that disrupt the shape of the membrane [7]. The amyloid fibrils are generally insoluble and transform into plaques. The $\mathrm{A} \beta$ oligomers are soluble and mainly spread throughout $\mathrm{AD}$ affected brain. Soluble $\mathrm{A} \beta$ oligomers deposited approximately $3-4 \mathrm{kDa}$ in the $\mathrm{AD}$ brain could affect the calcium ion channel activity in synapsis through disrupting nerve signal transmission and damage mitochondrial causes to increase free radial lead to cell death. Soluble oligomers reach $10-100 \mathrm{kDa}$, which is considered more cytotoxicity than amyloid fibril aggregation; thus, the soluble oligomers exposed higher toxicity when compared with an insoluble fibril structure [8]. The water-mediated attraction in A $\beta$ peptides and high propensity favor the formation of insoluble amyloid fibrils. The oligomers and fibrils conformation are recognized as a generic antibody epitope [9]. Although the relationship between oligomers and fibrils is still under debate, soluble and insoluble $\mathrm{A} \beta$ structures have been targeted to develop a cure for AD.

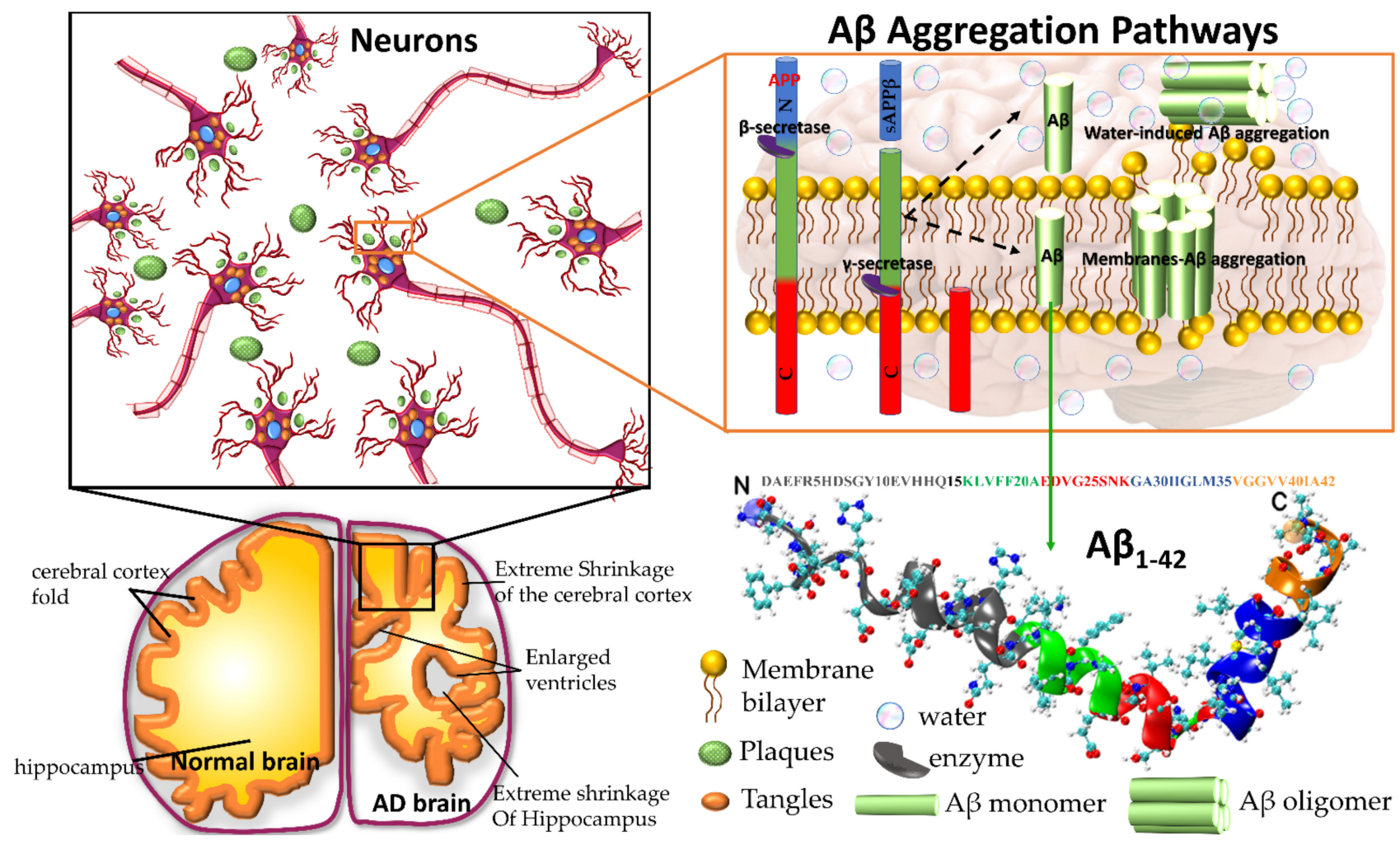

Figure 1. Plaques are around the neurons and tangles inside the neurons. Plaques and tangles are involved in killing the neurons resulting in drastic shrinking of the brain compared to normal brain. $\beta$-secretase cleaves APP (composed of 695 amino acids) into the membrane-tethered C-terminal fragments $\beta$ (CTF $\beta$ or C99) and $N$-terminal sAPP $\beta$. A $\beta$ is obtained after the sequential cleavage of CTF $\beta$ by $\gamma$-secretases. Upon APP cleavage, two mechanism pathways have been proposed, in the first, $A \beta$ is released to the extracellular environment, due to its hydrophobic nature, formed $A \beta$ aggregates, in the second, a small amount of $A \beta$ remains in the membrane evolving into membrane-associated $A \beta$ aggregates. $A \beta$ peptide has divided into five regions, $\mathrm{N}$-terminus or hydrophilic region represent in grey, Central hydrophobic region in green, Loop region in red, second hydrophobic region in blue and C-terminal in orange. AD brain shrunken as compared with Healthy one.

Molecular insight into aggregation pathways from oligomers to fibril formation remains an open problem in amyloidogenesis. A recent study reported [10] that during the aggregation, a large majority of oligomer structures are unstable and dissociate into their monomers instead of forming a new fibril structure, while the minority of the oligomers 
only convert into the fibril structure. Several research studies and hundreds of clinical trials since the early identification of the AD in 1906 have not been sufficient to discover an effective drug to alleviate the course of the AD disease [2], primarily due to the disordered nature of $A \beta$ proteins that remains challenging for therapeutics.

On 7 June 2021, the U.S. Food and Drug Administration (FDA) approved the aducanumab drug for mild AD patient treatment, which showed the removal of rich amyloid plaques and minimize side effects [11]. However, new drugs are required to cure AD completely. Many clinical trials with monoclonal antibodies targeting A $\beta$ peptides have given negative results such as failure to remove rich plaques and produced severe side effects. As a consequence of $\mathrm{A} \beta$ and tau proteins triggered to decline cognitions of AD patients $[12,13]$. Thus, targeting tau protein rather than $\mathrm{A} \beta$ could be a promising approach to design novel drugs against AD. In this brief review, we discuss the following topics regarding the computer simulation efforts devoted by researchers in recent years: (a) development of methods and force fields (FFs) for the study of intrinsically disordered proteins (IDPs), (b) role of metal ions in amyloid peptide aggregation, (c) perturbation of $A \beta$ peptide in membranes integrity and $(\mathrm{d})$ design of inhibitors against AD.

\section{Why Do Molecular Dynamics Simulations Cannot Accurately Quantify the A $\beta$ Structural Ensemble?}

Experimental studies have been unable to determine the properties of $A \beta$ peptide in solution due to the fast conformational changes and enhanced aggregation tendency. These studies have produced time- and space-average results that are difficult to map into a conformational state of folded and unfolded proteins. Computational simulations can make a time series at the atomic level that could help us explore the protein structure, dynamics, misfolding and aggregation mechanism, becoming a particularly suitable complement to experimental studies of conformational changes of $A \beta$. Several force fields (FFs) to study biomolecules have been developed in the last decades, such as AMBER, GROMOS, OPLS families, namely AMBER94, AMBER96, AMBER99, AMBER99SBildn, AMBER03, AMBER12SB, AMBER14SB, CHARMM22* CHARMM36, CHARMM36m, OPLS, GROMOS43a1, GROMOS43a2, GROMOS43a3, GROMOS53a5, GROMOS53a6 and GROMOS54a7. Most of the existing FFs describe phenomena associated with well-structured proteins. However, Saravanan et al. [14] concluded in a review study that the AMBER99SBILDN and CHARMM36m are highly optimized FFs and better choices for the characterization of IDPs such as $A \beta$ peptide. This statement is supported because these FFs rendered the well agreement with experimental NMR chemical shift and $\beta$-sheet content, and the AMBER99SB-disp [15] force field is also worth considering for the same purpose.

Five recent FFs Amber ff14SB, Amber ff14SB_idps, Amber ff99SB, CHARMM36, CHARMM36m have been used by Pawel et al. [16] to explore the large conformational space of monomeric $\mathrm{A} \beta 42$ peptide during $10 \mu$ s conventional molecular dynamics (MD) and 48 trajectories of replica exchange MD for $28.8 \mu$ s. These FFs provided better results than their predecessor older versions. The potential energy can be described by $E_{\text {total }}=E_{\text {bonded }}$ $+E_{\text {nonbonded }}$ where the bonded term $\left(E_{\text {bonded }}\right)$ consists of bond, angle, and dihedral-angle potentials, which explain the interactions of the atoms linked by covalent bonds, and the nonbonded term ( $\left.E_{\text {nonbonded }}\right)$ is constituted by van der Waals $(v d W)$ and electrostatic interactions. The electrostatic and vdW components are the primary contribution to nonbonded energy for monomeric $A \beta_{1-42}$. In the case of the CHARMM force field, the role of vdW interaction is reduced for $A \beta_{1-42}$ peptide and enhanced for the $A \beta_{1-42}$-water-ions interaction, whereas, in the case of Amber ff99SB, nonbonded potential energy slightly level up by the higher domination of electrostatic interaction, resulting in additional stabilization of the $\mathrm{A} \beta_{1-42}$ peptide related an over-structured $\beta$ sheet. The interaction with water molecules contributes to the dynamics, misfolded and self-assembly of the $A \beta$ peptide. The stronger solute-solvent interaction leads $A \beta_{1-42}$ to be less stable and more hydrophilic. In addition, MD simulation studies with CHARMM36m and FF14SB_IDPs show antiparallel $\beta$-sheets between residues $16-21$ and 29-36 of monomeric $A \beta_{1-42}$, and short a $\beta$-strand in the $C$ terminal of the same monomer, which is in excellent agreement with NMR studies [17]. 
AMBER_ff14SB and AMBER_ff99SB overestimated $\alpha$-helical and $\beta$-contents, respectively. Pawel et al. [16] strongly recommended using CHARMM36m force field for the study of the A $\beta 42$-water-ion complex system over the AMBER FFs.

It is a big challenge to determine an accurate description of the structure of IDPs through MD simulations based only on FFs. In this perspective, Chong et al. [18] reviewed advanced computational methods that employ protein configuration entropy and render a thermodynamic connection between structural disorder and protein properties. For example, the CHARMM and OPLS FFs exhibit lower average $\beta$-sheet content in dimers of $A \beta 42$ than that obtained with GROMOS 53a6 force field [18]. Subsequently, the average $\beta$-sheet content of the A $\beta 42$ dimers was found to be greater in OPLSAA [19] than in AMBERFF99SB [20]. Interestingly, both AMBER99SB-ILDN and OPLS/L FFs have produced results of the average secondary structure of $A \beta 42$ tetramer similar to each other [21].

The structural and thermodynamics properties of IDPs are susceptible to solutesolvent interaction compared to the folded protein. The choice of a reliable water model is necessary to characterize the $A \beta 42$ peptide. Chong et al. [22] performed an MD simulation to investigate the structural properties of $A \beta_{1-42}$ peptide by employing AMBER ff99SB force field with different solvent water models. They demonstrated that TIP4P-Ew exposed more $A \beta_{1-42}$-water interaction than conventional TIP3P water model [18]. They strongly encouraged using the TIP4P-Ew water model to investigate the $\mathrm{A} \beta_{1-42}$ peptide structural properties. In a review, Chong et al. [18] reported that existing FFs are insufficient to expose $\mathrm{A} \beta$ protein to water. Recently, the same problem has been addressed by a couple of groups. The first group [23] opted to scale the Lennard-Jones potential between atoms in proteins and oxygen atoms in water by factor 1.1 without disturbing water-water and water-protein interaction. The second group [24] introduced a new water model, TIP4P$\mathrm{D}$, which included an additional parameter in the TIP4P water model to overcome the deficiencies in water dispersion interaction.

Recently developed FFs and their default water model are tabulated in Table 1. Rahman et al. [25] have evaluated the accuracy of recent developed FFs ff99IDPs, ff14IDPs, ff14IDPSFF, ff03w, CHARMM36m, and CHARMM22* by performing MD simulations for two short peptides (HEWL19 and RS), five IDPs (HIV-rev, $\mathrm{A} \beta_{40}, \mathrm{~A} \beta_{42}{ }^{1 \mathrm{Z} 0 \mathrm{Q}}, \mathrm{A} \beta_{42}{ }^{\text {model }}$, and $\mathrm{pdE}-\gamma$ ) and two folded proteins (CspTm and ubiquitin) using trajectories of 1, 1.5, 5 or $10 \mu$ s for each system. They have compared J-coupling between MD simulation and NMR experiment for folded and disordered protein using different FFs. The J-coupling (J3- $\mathrm{HNH}_{2}$ and $\mathrm{J} 3-\mathrm{H} \alpha \mathrm{C}$ ) parameter measures the secondary structure distribution based on $\varphi$ backbone dihedral angle. Three IDPs FFs, ff99IDPs, ff14IDPSFF, ff14IDPs were in good agreement with the experimental J-coupling constant compared with tested FFs ff03w, CHARMM36m, and CHARMM22*. The balance between the local structural property (NMR chemical shift) and global structural property $(\mathrm{Rg})$ is still a challenging issue for molecular simulations of IDPs. Rahman et al., [25] noted two observations: (1) average $\operatorname{Rg}$ for $\mathrm{A} \beta 42^{1 \mathrm{Z} 0 \mathrm{Q}}$ is $12.1 \AA$ which is in close agreement with experimental $\operatorname{Rg} 12.4 \AA$, while ff03w showed Rg equal to $10.53 \AA$ and CHARMM 36 m displayed Rg about $13 \AA$, which suggests highly divergence among those FFs; (2) the three IDPs FFs render a good balance between secondary structures contents for both $A \beta_{40}$ and $A \beta_{42}$ model. While Amberff03w, CHARMM36m and CHARMM22* overestimated the $\alpha$-helical structure for IDPs, thus favouring folded protein structures. Therefore, the three specific IDPs FFs were developed by incorporating the changes made in the pre-existing FFs (Table 1 ) to enable an accurate description of the folded and misfolded proteins $[15,26-35]$. 
Table 1. Latest developed force field for intrinsically disordered protein and water model.

\begin{tabular}{|c|c|c|c|c|}
\hline Force Field & Parameter Set & Developments & Water Model & Reference \\
\hline \multirow{7}{*}{ AMBER } & ff99IDPs & $\begin{array}{l}\text { Updated from ff99SBildn by adding a set of } \\
\text { backbone torsion parameters of eight } \\
\text { disordered promoting amino acids. }\end{array}$ & TIP3P & Wei Y et al. [26] 2015 \\
\hline & ff14IDPs & $\begin{array}{l}\text { Updated from ff14SB by embedding a set of } \\
\text { backbone torsion parameters of eight } \\
\text { disordered promoting amino acids. }\end{array}$ & TIP3P & Song et al. [28] 2017 \\
\hline & ff14IDPSFF & $\begin{array}{l}\text { Updated from ff14SB by introducing a set of } \\
\text { backbone torsion parameters for } 20 \\
\text { amino acids }\end{array}$ & TIP3P & Song et al. [29] 2017 \\
\hline & ff03CMAP & $\begin{array}{l}\text { Updated from ff03 by introducing a correction } \\
\text { maps (CMAP)-optimized force field }\end{array}$ & $\begin{array}{c}\text { TIP4PD } \\
\text { (Modified the } \\
\text { dispersion interaction } \\
\text { of the TIP4P) }\end{array}$ & Zhang et al. [30] 2019 \\
\hline & ff14SB & $\begin{array}{l}\text { Updated from ff99SB by improving the } \\
\text { Accuracy of Protein Side Chain and } \\
\text { Backbone Parameters }\end{array}$ & TIP3P & Maier et al. [31] 2015 \\
\hline & $\mathrm{ff} 03 \mathrm{w}$ & $\begin{array}{l}\text { Updated from ff } 03 \text { by adding slight } \\
\text { backbone modification }\end{array}$ & TIP4P/2005 & Best et al. [32] 2010 \\
\hline & A99SB_disp & $\begin{array}{l}\text { Update from a99SB-ILDN by an introducing } \\
\text { small change in the protein and water vdW } \\
\text { interaction terms }\end{array}$ & TIP4P-D & Robustelli et al. [15] 2018 \\
\hline \multirow{4}{*}{ CHARMM } & CHARMM36m & $\begin{array}{l}\text { Updated from CHARMM } 36 \text { by a refined } \\
\text { backbone correction map potential }\end{array}$ & CHARMM-modified TIP3P & Huang et al. [33] 2017 \\
\hline & CHARMM36IDPSFF & $\begin{array}{c}\text { Updated from CHARMM } 36 \mathrm{~m} \text { by CMAP } \\
\text { corrections made for all } 20 \text { naturally occurring } \\
\text { amino acids }\end{array}$ & CHARMM-modified TIP3P & Liu H et al. [34] 2019 \\
\hline & CHARMM22* & $\begin{array}{l}\text { Updated from CHARMM by introducing } \\
\text { modifications in backbone torsion potential }\end{array}$ & CHARMM-modified TIP3P & Stefano Piana et al. [35] 2011 \\
\hline & CHARMM36mW & $\begin{array}{l}\text { Van der Waals interaction between protein } \\
\text { and water are included in CHARMM } 36 \mathrm{~m}\end{array}$ & CHARMM-modified TIP3P & Samantray et al. [27] 2020 \\
\hline
\end{tabular}

The inconsistency of empirical physical models used in MD techniques can impact FFs and water models that affect the simulation result's accuracy. Researchers have strived hard to develop perfect FFs to improve IDPs description; they aim to describe the high flexibility of these proteins, thus enlarging the conformational ensemble and increase the possibility of locating them in different local minima. Mu et al. [36] reported a couple of ideas to improve the accuracy of FFs for IDPs structural characterization, (1) Modification of force field parameters aided by global optimization, and (2) Maintaining a good balance between secondary structure via reparameterization (backbone dihedral parameters and $\mathrm{vdW}$ interaction between water-protein interaction) of existing FFs. One of the most common problems among the IDPs force field is over-stabilizing protein-protein interaction that impacts the aggregation mechanism of IDPs. Due to the IDPs force field's inaccuracy, Mu et al. [36] encouraged improving backbone dihedral parameters and Lennard-Jones potential parameter (protein-water interaction) in the existing IDPs FFs and obtained training data from experimental observation and quantum chemical calculation. Undoubtedly, both reparameterization and training strategies may assist in new FFs development.

Another option to the atomistic FFs is to employ state-of-the-art coarse-grained (CG) models that not only sample more efficiently the entire space of protein conformations for large systems but also allow simulations for longer time scales of hundreds of $\mu \mathrm{s}$ [37], generally forbidden by brute force all-atom MD simulation and very relevant for biological processes [38] (e.g., folding, allosteric communications, conformational changes under mutations, self-assembly process, etc). Some popular CG FFs such as UNRES has been employed to study the fibril formations initiated by templates of $A \beta_{40}$ fragments [39] capturing the dock-lock mechanism and similar the crowding effect of fragments was studied by PRIMO CG FF [40]. MARTINI 2 was employed to unveil the aggregation and organization of short A $\beta 16-22$ peptides in lipid membranes [41]. The abovementioned CG FFs capture processes in time scales inaccessible atomic FFs, but yet they were restricted by system size or a lack of flexibility in secondary structure transitions. In this regard, the 
new release of MARTINI 3 force field aided by Gō-Like model [42-45] can become a new tool for realistic exploration of full-length $A \beta$ peptide aggregation in contact with complex lipid-cholesterol membranes. Marrink group has made large efforts to develop a library of different lipid species (i.e., about 63 types) consistent with human plasma cells [46]. Following this idea, Poma et al. [47] have employed a very simplified CG model [48] to unveil the mechanical properties of $A \beta 40$ and $A \beta 42$ fibrils under different mechanical deformation process (e.g., tensile, indentation and shearing stresses) [49] and more recently they investigated [50] the change in mechanical stability between the oligomer and matured fibrils. The soluble oligomers are characterized by a length size about 3 to $5 \mathrm{~nm}$, whereas $\mathrm{A} \beta$ fibrils typically reach hundreds of $\mathrm{nm}$ (see Figure 2). It is well-known the inverse relationship between toxicity and the length of the $A \beta$ assembly [51]. Oligomers are considered more toxic than fibrils because of their high degree of flexibility toward low molecular weights, and the possibility of forming hydrophobic structures that may impair cell functions. Instead, fibrils are more thermodynamic stable and stiffer and less capable to undergo transitions to smaller and more toxic assemblies. Over the years, still some questions still remain open in terms of the mechanical characterization in amyloidogenesis and $A \beta$ aggregate maturation: (a) what is the major role of the mechanical stability during $A \beta$ oligomerization (e.g., tetramer, hexamer, etc)? (b) is the toxicity of oligomers which are closer to the membrane correlated by a minimum of mechanostability of $A \beta$ peptide complexes, (c) how is the gain in mechanical stability from oligomers to fibrils involved in disease progression? and (d) Can we devise new strategies to reduce the mechanical stability of oligomer-to-fibril step through small molecular breakers (i.e., drugs recognition process)? To provide new answers to those open problems, new research combining versatile CG FFs and single molecule force spectroscopy is highly advised. For instance, in MD simulations, one can trace hydrophobic native interactions in equilibrium and simultaneously during a deformation process. Hence, the idea of hydrophobic structures can find support in molecular simulations as the main driving force for cell damage. Furthermore, molecular pathways could elucidate the critical conformation that maintains the mechanical stability of the $A \beta$ assembly in the single-molecule force spectroscopy experiment. Figure 2 depicts the most relevant structure during aggregation and current methodologies used for its computational characterization [50,52].

Samantray et al. [35] have examined recently developed IDPs FFs, namely AMBER99SB-disp, CHARMM36m, and CHARMM36 with enhanced protein-water interactions (CHARMM36mW) for the study of $A \beta_{16-22}$ (wildtype) aggregation and its mutation F19L $A \beta_{16-22}$ (mutation 1) and F19 V/F20 V A $\beta_{16-22}$ (mutation2), as model systems for testing purpose. In AMBER99-disp, the peptide-water interactions are increased too much resulting in an inhibition of the $A \beta 16-22$ aggregation. The same trend has been observed in the simulation with the AMBERFF03w force field [53]. The difference between CHARMM36m and CHARMM36mW is a reparameterization of the protein-water interaction. In contrast, an experimental study [54] reported the following aggregation order mutation $1>$ wildtype $>$ mutation $2 \approx 0$. AMBER99-disp does not apply for $A \beta$ aggregation process because the interactions between peptide and water are drastically increased, leading to inhibition of the aggregation pathway. The CHARMM36mW can provide aggregation rate in the order of wildtype>mutation1>mutation2. Thus, FFs cannot reproduce the aggregation of $A \beta$ peptide observed in experiments, but they maintain a better balance between peptide-water and peptide-peptide interaction. These results imply that improving the force field significantly impacted the simulation aggregation pathway than modifying the protein sequence. Samantray et al. [35] strongly encourage the use of CHARMM $36 \mathrm{~mW}$ for studying a full-length $A \beta$, even though it is not a perfect force field, since it yielded a promising result for aggregation benchmark. Nevertheless, reparameterization of this specific force field is still required. 


\begin{tabular}{|c|c|c|c|}
\hline $\begin{array}{c}\text { A } \beta \text { peptide } \\
(<3 \mathrm{~nm})\end{array}$ & $\begin{array}{c}\mathrm{A} \beta \text { oligomer } \\
(3-5 \mathrm{~nm})\end{array}$ & $\begin{array}{c}\text { A } \beta \text { fibril } \\
(20-100 \mathrm{~nm})\end{array}$ & $\begin{array}{c}\text { A } \beta \text { plaques } \\
(>1000 \mathrm{~nm})\end{array}$ \\
\hline & & & \\
\hline \multicolumn{4}{|c|}{ Computation model for $A \beta$ study } \\
\hline AA-MD & AA-MD & CG-MD & CG-MD/continuum theory \\
\hline \multicolumn{4}{|c|}{ Young's elastic modulus (Y) } \\
\hline$\sim 10^{2} \mathrm{MPa}$ & $\sim 1 \mathrm{GPa}$ & 3-10 GPa & $\sim 1 \mathrm{GPa}$ \\
\hline
\end{tabular}

Figure 2. Representation of $A \beta$ structures during aggregation: free $A \beta$ peptide, oligomers, fibrils and plaques. Typical lengths are given for peptide $(<3 \mathrm{~nm})$, oligomers $(3-5 \mathrm{~nm})$ and fibrils $(20-100 \mathrm{~nm})$. All-atom MD (AA-MD), coarse-grained MD (CG-MD) and continuum models have been employed to unveil the mechanical stability for each structure. Young modulus $(\mathrm{Y})$ defined by the ratio of applied tensile stress to a given strain provides an idea of the elastic regime. $\mathrm{Y}$ values for each structure is taken from ref (50 and 51). Some images are modified with permission of BrightFocus Foundation.

Lockhart et al. [55] performed REMD simulations to examine the impact of the three popular FFs, CHARMM22 (protein FF) with CHARMM36 (lipid FF), CHARMM36m (protein FF) with CHARMM36 (lipid FF), and Amber14SB (protein FF) with Lipid14 (lipid $\mathrm{FF}$ ), for the binding mechanism between the $A \beta_{10-40}$ and the Dimyristoylgylcerophosphocholine (DMPC) bilayers. These three FFs have shown similar results in subjects like (a) stable helix formed in C-terminal of the peptide, (b) C-terminal of the peptide inserted into the bilayer hydrophobic core, (c) the thickness of the bilayer induced by the peptide about $10 \AA$ and d) the disordered effect induced by the peptide on the fatty acid tails in the DMPC lipids. Nevertheless, these three FFs yielded different conformation ensembles of the peptide and bilayer that do not disturb the binding of the peptide with the bilayers.

Coskuner et al. [56] have reviewed several studies extensively and suggested that widely used FFs CHARMM, AMBER, GROMOS and OPLS, cannot produce accurate results for disordered entities. Even more, all existing computational techniques were designed to describe phenomena in ordered protein systems rather than in disordered protein structures. Important to mention that, Density Functional Theory (DFT) suffered from a number of errors that originated in the approximation of exchange-correlation functionals. These errors have been identified as the underestimation of barriers in describing chemical reactions, the band gaps, charge transfer excitation energies, and binding energies of charge transfer species in a biomolecule. DFT is the basis for constructing FFs such as CHARMM, AMBER, GROMOS and OPLS for intrinsically disordered protein and their complexes with ligands. These FFs are associated with an approximate exchange-correlation function that may lead to mistakes during prediction of the structural properties of IDPs. Notably, overcoming deficiencies of the exchange-correlation functional in DFT will help to improve the accuracy of IDP FFs.

\section{Why Does $\mathrm{A} \beta$ Peptide Perturb Membrane Integrity?}

Three models [13] have been proposed for small protein insertion in lipid bilayers, (a) membrane pore formation model: $A \beta$ oligomers formed within the membrane facilitates well-defined pores that lead to an unbalanced flow of ions in and out of the membranes, 
(b) carpeting model: $\mathrm{A} \beta$ peptide contacts the membrane surface to produce asymmetric pressure between two lipid layers of the membrane, which causes small molecules leakage, (c) detergent-like effect model: the lipids leave from the cellular membranes interacts with the $A \beta$ peptide in resulting from perturbing membrane integrity. In this context, these models perturb the membrane through the interaction of $A \beta$ peptide that yields to cell toxicity. Computer simulations assist in examining these models to unveil the molecular mechanism of the $A \beta$-membranes interaction. In general, three fundamental questions have not been elucidated yet, (1.) How does $A \beta$ oligomeric intermediate perturb membrane integrity? (2.) What are the specific residues involved in membranes- $\mathrm{A} \beta$ interaction? (3.) What is the impact of metal ions in the mechanism of interaction between $\mathrm{A} \beta$ and membranes?

\subsection{A $\beta$ Monomer-Membrane}

Although the $\mathrm{A} \beta$ peptides monomers were dissolved in non-polar environment, water solution and micelles environment using NMR techniques, there are no experimental studies on the 3D structure of monomers within the membrane environment [57]. In this perspective, computer simulations have been employed to unveil the interaction mechanism between truncated or full-length monomers and various types of membranes. For instance, MD simulations [58] subjected to examine the $\alpha$-helical conformation (pdb id: $1 \mathrm{Z0Q}$ ) and $\beta$-sheet conformation ( $\mathrm{pdb}$ id: $2 \mathrm{BEQ}$ ) of the $\mathrm{A} \beta_{1-42}$ peptide behavior on zwitterionic dipalmitoylphosphatidylcholine (DPPC) and anionic dioleoyl phosphatidylserine (DOPS) membranes, demonstrated that both membrane surfaces attract $A \beta_{1-42}$ peptide, the attraction promotes dual mechanism, (a) the peptide perturbs the membrane surface and $b$ ) then $A \beta_{1-42}$ follows aggregation by peptide-peptide interactions. Subsequently, REMD simulations were recruited to explore the same peptide in the same membranes [59], showing that no $\beta$-hairpin was found in the peptide except unstable $\beta$-hairpin on the anionic DOPS membrane, and the salt bridge Asp23-Lys28 gives significant contribution in the $\beta$-hairpin conformation of $A \beta_{1-42}$ fibril and it is not formed in the membrane surface due to the Lys 28 made electrostatic interaction with the charged lipid of the membranes.

Lockhart et al., [60] have employed REMD simulations to study the binding between $\mathrm{A} \beta_{10-40}$ monomer and the DMPC bilayer in the presence of calcium ions. Results suggested two observations (a) the Asp23-Lys28 salt bridge is destabilized by the calcium ions and it is compelled to Lys28 interacts with the bilayers and (b) calcium ions reinforce the interaction between the monomer and the membranes by robust electrostatic interaction of charged amino acids to lipid polar head groups. These driving forces seemed to assisted the monomer in penetrating the lipid membranes.

In vitro studies reported faster aggregation of $A \beta 2_{5-35}$ compared to the full-length of $A \beta$ peptide [61,62]. Smith et al. [63] probed the binding character of the $A \beta_{25-35}$ and $A \beta_{10-40}$ with the zwitterionic DMPC bilayer using REMD simulation and discovered two states when $A \beta_{25-35}$ binding to bilayers, stable state-bound: peptide binding to surface polar head groups of the membrane, and less stable state: peptide inserted in the bilayer hydrophobic core. Free energy calculations confirm the $A \beta_{25-35}$ transition between surfacebound and insertion state. In the case of the inserted state, the $A \beta_{25-35}$ induces minor depletion in the lipid structure. In contrast, the C-terminal of the $A \beta_{10-40}$ penetrates the bilayer deeply, inducing severe damage to membrane integrity, and thus, it confirmed the binding mechanism of $A \beta_{25-35}$ and $A \beta_{10-40}$ as different from each other.

\subsection{A $\beta$ Dimer-Membrane}

The dimer of $A \beta_{17-42}$ peptide insertion-membrane-pathway was examined using explicit solvent molecular dynamic simulations [64], with the structure extracted from the NMR data of $A \beta_{1-42}$ fibril (PDB code: $2 B E G$ ) and with a U-shaped conformation and $\beta$-strand-turn- $\beta$-strand motif. The five different dimer configurations were generated, constructed the dimer on and in the lipid bilayer namely dimer1, dimer 2, dimer3, dimer4 and dimer5. Dimer1 was placed at the bilayer surface in the upper bilayer leaflet and is 
barely interacting with the bilayer leaflets. The dimer2 to dimer4 are partially embedded in the bilayers, and dimer5, fully immersed into the bilayers. The five different initial conformations of the dimers show different behavior on the DOPC (Dioleoyl, 1,2-dioleoylsn-glycero-3-phosphocholine) bilayers during the simulation. Jang et al. [64] have found that dimer structures reached equilibration more quickly in the membrane-embedded state than when dimers interact with the surface of the bilayer. Dimer1 slightly diffused into the bilayers with decreased beta-sheet contents, Dimer2 got inserted into the bilayer with modified initial conformation, Dimer3 managed to get inserted in the bilayer with loss of beta-sheet, Dimer4 was partially inserted with U-shaped conformation deviated significantly from initial conformation and finally, Dimer5 was deeply inserted into the bilayer preserving the U-shaped. Dimer 2 and 5 have maintained the U-shaped. These results demonstrated that $\mathrm{U}$-shaped dimer is a more stable conformation observed both in solution and in the membrane. These structures are capable of penetrating the membranes that lead to the proposed mechanism of membrane toxicity.

Davis et al. [65] performed MD simulations to examine the dimer formation of $A \beta_{1-42}$ peptide on zwitterionic DPPC and anionic DOPS membrane surfaces and found that both membranes promoted $A \beta_{1-42}$ dimer formation. The DOPS membrane promotes the strong peptide-peptide interaction within the dimer exposed to solvent for the peptide aggregation. An opposite trend is followed by DPPC membranes in which peptide-peptide interaction becomes weaker during dimerization due to the strong interaction between peptide and lipid. These observations supported that DOPS rather than DPPC manifested the dimer process rapidly for $\mathrm{A} \beta_{1-42}$ peptide aggregation and in addition, DOPS served as a catalyst in the peptide aggregation.

Researchers have thought that two proteins, tau and amyloid, cause the AD disease for long decades. In contrast, Snowden et al. [66] proposed the hypothesis that Omega-3 and Omega- 6 fatty acids are responsible for protective and pathogenic effects in AD. Lu et al. [67] have performed MD simulations to explore the structural character of $A \beta_{29-42}$ dimer within the Omega-3 (docosahexaenoic acid) and Omega-6 (arachidonic acid) fatty acids membranes. Their results are compared with the $A \beta_{29-42}$ dimer inserted into 1-palmitoyl-2-oleoyl-sn-glycero-3-phosphocholine (POPC) membrane system. MD simulations show that omega-3 membranes induced a higher population of the dimer disordered than in omega- 6 membrane, mainly due to the decrease of beta-sheet and increase of helical content. Both fatty acid membranes yielded new conformations and orientation of the dimer compared to the POPC membrane.

\subsection{A $\beta$ Trimer/Tetramer-Membrane}

$A \beta$ toxicity is significantly linked to its binding to the cell membrane and causes neuronal cell death. Jana et al. [68] have used mouse cortical neuronal culture to test the correlation between $\mathrm{A} \beta$ oligomer (up to tetramer level) binding and cell viability. Mouse cortical was treated with $5 \mu \mathrm{m}$ concentration of $A \beta$ peptide for $96 \mathrm{~h}$, A $\beta 42$ peptide binding to neurons is 7-fold to 10-fold higher than that of $A \beta_{1-40}$, which binds neurons after $24 \mathrm{~h}$. Surprisingly, tetramers and trimers are observed after $48 \mathrm{~h}$ with less than $5 \%$ of total bound $A \beta$, and the peptide has not become toxic up to $48 \mathrm{~h}$ with 590 femtograms $A \beta /$ cell bound. The peptide concentration was increased up to $15 \mu \mathrm{m}$ and significant changes were observed when $A \beta 42$ binding rate reached 777-923 femtogram $A \beta /$ cell at 72 and $96 \mathrm{~h}$, being neurotoxic triggered cell death and allowing trimers and tetramers to bind gradually to neurons, increasing over time for $A \beta_{1-42}$ and contributing $15-20 \%$ of the total bound. The cell-bound trimer and tetramer (not monomer and dimer) play a vital role in $A \beta_{1-42}$ toxicity (Figure 3). Small efforts exist on this matter, and researchers are highly encouraged to explore the $\mathrm{A} \beta$ trimer and tetramer peptides on the surface of membranes and within membranes using multiscale MD simulation to unveil cell toxicity mechanisms. 


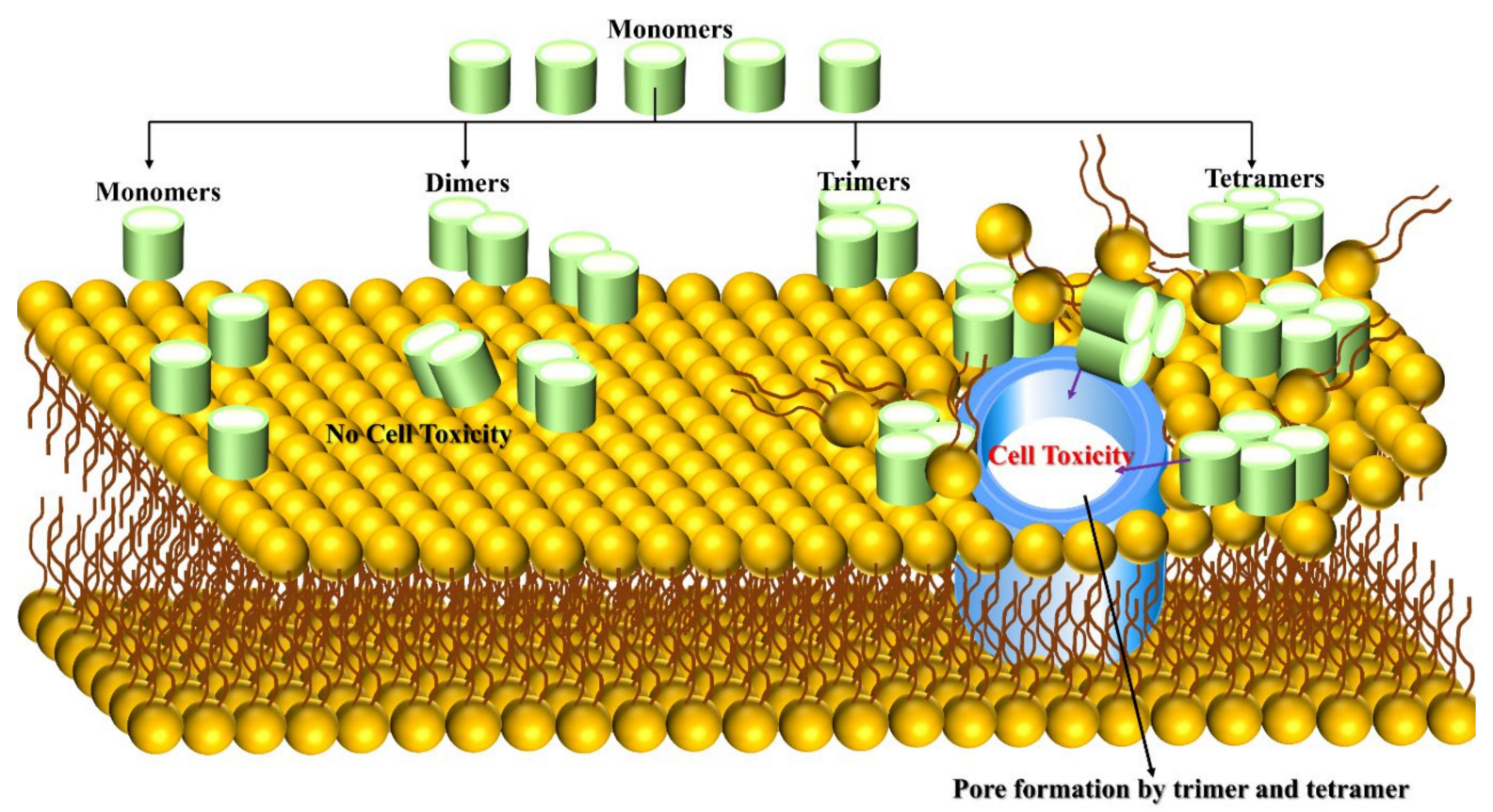

Figure 3. $A \beta$ monomers and dimers interacting with membrane bilayers do not cause cell toxicity but tetramers followed by trimer binding causes the cell toxicity.

A2V, H6R, D7N, A21G, E22Q, E22G, D23N mutations in A $\beta$ peptides play a vital role to developing the disease in patients. On the other hand, A2T mutations protect patients from the AD because this mutated APP prevents the $\beta$-secretase cleavage [69]. We comment on some computational efforts about this topic. To gain knowledge of $A \beta$ trimer neurotoxicity, Ngo et al. [70] carried out REMD simulations of $A \beta_{11-40}$ trimer within DPPC lipid bilayer. They found that van der Waals interactions are the principal driving force for the binding between the trimer and lipid membrane, resulting in the penetration of the trimer in the bilayers. On the other hand, A21G [71] and F19W [72] mutations in the trimer decrease the presence of ASP23-LYS28 salt bridge, which leads to a destabilization of the trimer within the DPPC membranes. These mutations of $A \beta_{11-40}$ trimers implied a lower aggregation tendency and reduced stability within the membrane compared to wild-type truncated trimer. The opposite trend is observed in the D23N mutant of the trimer. The D23 is a crucial residue as it forms Asp23-Lys28 salt-bridge in the loop region. The D23G mutation can reduce the total charge of oligomers, which causes a decrease in electrostatic energy of contacts between D23G in mutated $A \beta_{11-40}$ monomers and promotes faster self-assembly and aggregation.

Arctic mutation (E22G) in $A \beta_{1-42}$ peptides has been found in the human brain, enhancing $A \beta_{1-42}$ aggregation, toxicity and playing a significant role in early-onset $A D$ development. Poojary et al. [73] have tested the effect of $A \beta_{1-42}$ mutations [74,75] in monomeric and tetrameric forms within the POPC membranes by using 500ns molecular dynamic simulations of native and mutated (E22G, D23G, E22G/D23G, K16M/K28M, and K16M/E22G/D23G/K28M mutants) A $\beta_{1-42}$ peptide. The simulation results demonstrated that the monomeric and tetrameric structure of E22G mutated $A \beta_{1-42}$ possesses higher stability, D23G mutant is the most unstable among the other studied peptides. Compared to other studied peptides, the tetramer of the D23G mutant exhibits an increased ability to perturb the membrane, which causes water permeation into the membrane. The pieces of evidence show that the tetramer of the D23G mutant has the highest toxicity, but the native and mutant monomer species are not toxic.

An early experimental study [76] failed to observe water molecules inside the $A \beta$ fibril, but recent solid-state NMR studies $[77,78]$ confirmed water molecules deep buried in the fibril which have been corroborated by MD simulations [79]. The difference between water molecule distribution in oligomers and fibrils remains an open question that deserves 
further exploration as water leakage has a crucial role in neurotoxicity. In this perspective, Nguyen et al. [21] address why the oligomers are more toxic than fibrils. They have identified the conformational space of $A \beta_{1-42}$ tetramer (smallest stable oligomers) using coarse-grained FFs. They employed MD simulations to examine A $\beta$ structural stability and compared them to NMR fibril structures. Thus, they proposed that the water density inside the oligomer is greater than in fibril, causing it to enhance the toxicity of oligomers. The interaction mechanism between tetramer and membranes interaction has yet been elusive, the open challenge question to the researcher is to investigate the smallest oligomer (A $\beta_{1-42}$ tetramer) dynamic behavior on or within membranes (water-lipid interaction) by using computer simulations. This important piece of information will assist in unveiling neurotoxicity more quantitatively.

\subsection{A $\beta$ Oligomer-Membrane}

Despite many efforts made in the amyloid pore hypothesis, none of the studies provides the atomic structure of $A \beta$ oligomers. Without this information, it is impossible to elucidate the mechanism of $A \beta$ oligomers toxicity. In this regard, Serra-Batiste et al. [80] examined the $A \beta$ behavior within the membrane to elucidate the neurotoxicity in $A D$ and found that $A \beta_{1-40}$ and $A \beta_{1-42}$ exhibited different physical behavior, $A \beta_{1-40}$ aggregated into amyloid fibril while $A \beta_{1-42}$ assembled into oligomers. The $A \beta_{1-42}$ oligomers adopted $\beta$-barrel arrangement and formed well-defined pore into a membrane that named by $\beta$-barrel-pore-forming $A \beta_{1-42}$ oligomers $\left(\beta \mathrm{PFOS}_{\mathrm{A} \beta 42}\right)$. In comparison with $\mathrm{A} \beta_{1-40}, \mathrm{~A} \beta_{1-42}$ has a significant role in $\mathrm{AD}$ by the higher propensity of $\beta \mathrm{PFOS}_{\mathrm{A} \beta 42}$.

Carulla's group further investigated [81] the atomic structures of $A \beta_{1-42}$ tetramers and octamers within the membrane using experimental and MD simulations studies. The $A \beta_{1-42}$ tetramer consisted of the six-stranded $\beta$-sheet core, $A \beta_{1-42}$ octamers constituted by two $A \beta_{1-42}$ tetramers, and both tetramer and octamers surrounded by a membrane. In the simulation study, the hydrophilic residues placed in both tetramers and octamers edges are unfavourably exposed to the hydrophilic lipid tails of the membrane. The head group of the membrane is reoriented towards hydrophilic edges of tetramers and octamers leading to stabilizing of the lipid-protein complex and resulting in lipid-stabilized pores. A high degree of water permeation is observed in the membrane and higher solvent accessible surface area in the octamers than tetramers. The water and ion penetration in the membrane was identified experimentally. Simulation and experimental results together proposed that water and ion penetration occurred through lipid-stabilized pores, mediated by hydrophilic amino acids in the $\beta$-sheet edges of the oligomers that could be responsible for neurotoxicity in AD.

Smith et al. [82] used replica exchange MD simulation for studying the aggregation of the $\mathrm{A} \beta_{25-35}$ peptide within the DMPC bilayer using CHARMM22/CMAP correction and CHARMM36 FFs for peptide and lipid FFs, respectively. In general, the A $\beta_{25-35}$ peptide is characterized by two regions $\mathrm{N}$-terminal (residues 25-28) and C-terminal (residues 29-35). The hydrophobic and electrostatic interactions between the $\mathrm{A} \beta_{25-35}$ dimers drives to produced parallel out-of-registry aggregation, which manifested pore formation in the bilayer. In particular, the aggregation within the membrane is constituted by three concentric rings, two outer rings located in the upper and lower leaflets are in contact through hydrophobic $\mathrm{C}$-terminal with the bilayer core and $\mathrm{N}$-terminal pointing towards the lipid head groups. The third rings are closer towards the pore centre, N-terminal directed the pore center to create pore lining. The peptide aggregation increases the extent of bilayer thinning that is more than four-fold more significant than the monomeric species; mainly because the dimers reduce the thickness of the DMPC bilayer from $40 \AA$ to $24 \AA$. Thus, extensive damage to the membrane bilayers was mediated by uncontrollable $\mathrm{Ca}^{2+}$ permeation.

Conventional and steered MD simulations [83] have been employed to explore the zwitterionic POPC and palmytoil-oleoyl-phosphatidylethanolamine (POPE) head groups that influence the interaction between $A \beta_{9-40}$ octamers and lipids. The results demon- 
strated that the POPC head groups form weaker electrostatic interaction with the $A \beta$ octamer which have shorter-lived contact with the bilayers. Immediately, the head groups reorganized themselves, resulting in the lipid tail moving upwards to enhance electrostatic contact with the $\mathrm{C}$-terminal of the octamer, which led to $\mathrm{A} \beta$ insertion into the membrane. This process is called a detergent-like effect on membranes for amyloid peptide formation. Whereas in the case of POPE-A $\beta_{9-40}$ octamers, the head group repels the peptide insertion into membrane, this barrier is overcome by the stronger electrostatic interactions that persisted between charged residues in the $A \beta_{9-40}$ and lipids bilayer and causing the C-terminal of the peptide to be inserted in the bilayer.

Qiang et al. [84] have used solid-state NMR spectroscopy to probed the phospholipids dynamics and interactions between lipid and peptide in a POPC bilayer fused with $\mathrm{A} \beta_{1-40}$ oligomers. At physiological conditions, lipids show changes in terms of lipid motion and reorganization. The stronger lipid- $\mathrm{A} \beta_{1-40}$ interactions restrict the lipid motion and inter-strand interaction between the loop and C-terminal of the oligomers. This effect is weakened by the lipid molecules inserted into oligomers that form rapid aggregates along with membranes intercalated by a hydrogen bonding network. The loop region of the oligomer could interact with the lipid head group to severely disturb membrane integrity by weakened interactions between lipid bilayers.

Fernández-Pérez experimental study [85] examines the relationship between cholesterol and $\mathrm{A} \beta$ oligomers behavior in a membrane. The membrane perforation induced by $A \beta$ is much faster when a low concentration of cholesterol is present in the membrane. In contrast, a high concentration of cholesterol blocks the perforation effect of $A \beta$. Interestingly, neurons treated with cholesterol significantly increased $A \beta$ association in the membranes compared with the free cholesterol. This evidence supports that the perforation effect of $A \beta$ depends on the amount of cholesterol in the membrane and that cholesterol has a protective effect for $A \beta$ toxicity. A large number of studies [13] provided evidence that cholesterol promotes $A \beta$ aggregation and neurotoxicity.

Neurotoxicity of the $A \beta$ has been elucidated by studies of the different forms of the $\mathrm{A} \beta$ peptide that interact with phosphatidylcholine $(\mathrm{PC})$ and cholesterol. A dual mechanism has been observed [86], (a) The low concentration of cholesterol in the membrane interacts with $A \beta$ peptide to promote the peptide insertion into the membrane and (b) opposing the peptide permeation at elevated cholesterol concentration through membrane stiffness effect. It gives evidence that Cholesterols manifested $A \beta$ neurotoxicity [87-91]. In contrast, PC inhibits neurotoxicity by blocking aggregation and $\beta$-sheet formation $[92,93]$.

The impact of cholesterol on the binding of $A \beta\left(A \beta_{17-42}\right.$ and $\left.A \beta_{11-42}\right)$ fibrils with DPPC bilayers was investigated through MD simulations using Martini 2.0 force field [94]. The MD results supported the electrostatic interaction as the major driving force for the fibril binding to the membranes, along with the elevated level of cholesterol present in the membrane, which modulates this interaction by a dual mechanism, i.e., to the increased binding of positive residues with the lipid head groups and enhanced $\mathrm{Ca}^{2+}$ binding with the bilayers. The high concentration of cholesterol promotes $\mathrm{A} \beta_{1-42}$ peptide binding to the bilayer, in contrast, the cholesterol prevents the insertion of $A \beta_{10-40}$ peptide into the bilayer. The relationship between $A \beta$ peptide and membrane co-incubated with cholesterol is unclear, and computer simulations are still required to shed light onto this interaction.

\section{How Do Metal Ions Govern A $\beta$ Peptide Behavior?}

The senile plaques are enriched by the presence of $\mathrm{Zn}^{2+}, \mathrm{Cu}^{2+}, \mathrm{Fe}^{3+}$ and $\mathrm{Al}^{3+}$ metal ions, it has been observed that in the case of a postmortem $\mathrm{AD}$ brain [95] their concentrations are $0.4 \mathrm{mM}$ of $\mathrm{Cu}^{2+}, 1 \mathrm{mM}$ of $\mathrm{Zn}^{2+}$, and $1 \mathrm{mM}$ of $\mathrm{Fe}^{3+} ; \mathrm{Al}^{3+}$ has been also found in greater concentration in isolated core of senile plaques [96]. We will describe computational simulation efforts of metal interaction with $\mathrm{A} \beta$ peptides in the following sections. 


\subsection{Cu and $\mathrm{Zn}$ Ions Interactions with $A \beta$ Peptides}

In general, metal ion binding to peptide has been divided into three approaches, namely (a) bonded, (b) non-bonded, and (c) cationic dummy atomic models. Our previous research elucidated the dynamics of $A \beta$ peptides upon metal interaction with bonded and non-bonded approaches $[97,98]$. For the non-bonded, we found $A \beta_{1-40}-Z^{2+}$ and $A \beta_{1-42^{-}}$ $\mathrm{Zn}^{2+}$ adopted a $\beta$-hairpin structure. For the bonded approach, the conformational space of $A \beta_{1-42}-Z n^{2+}$ is more heterogeneous compared to that of $A \beta_{1-42}-C u^{2+}$ and $A \beta_{1-42}$ because of the large number of basins present in the free energy surface (FES) of $A \beta_{1-42}-\mathrm{Zn}^{2+}$ (see Figure 4). It confirmed that $A \beta_{1-42}-Z^{2+}$ aggregates lead to a more amorphous state compared to other cases. In addition, we found that $\mathrm{Zn}^{2+}$ rather than $\mathrm{Cu}^{2+}$ binding promotes greater hydrophobicity in $A \beta_{1-42}$. Our result agrees with Miller et al. [99] studies. They monitored the role of $\mathrm{Zn} 2+$ ions on $\mathrm{A} \beta$ oligomers by using MD and REMD simulations with the CHARMM27 force field. They observed that $\mathrm{Zn}^{2+}$ binding decreased the solvation energy (increase hydrophobicity) of $A \beta$ oligomer, which enhanced the aggregation propensity, and that a higher concentration of $\mathrm{Zn}^{2+}$ could reduce aggregation kinetics. In contrast, the aggregation process became much faster than in metal-free solutions.

A

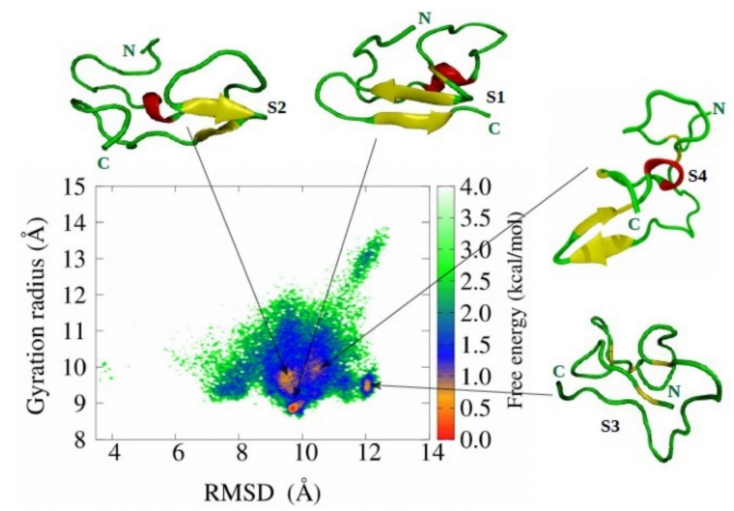

B

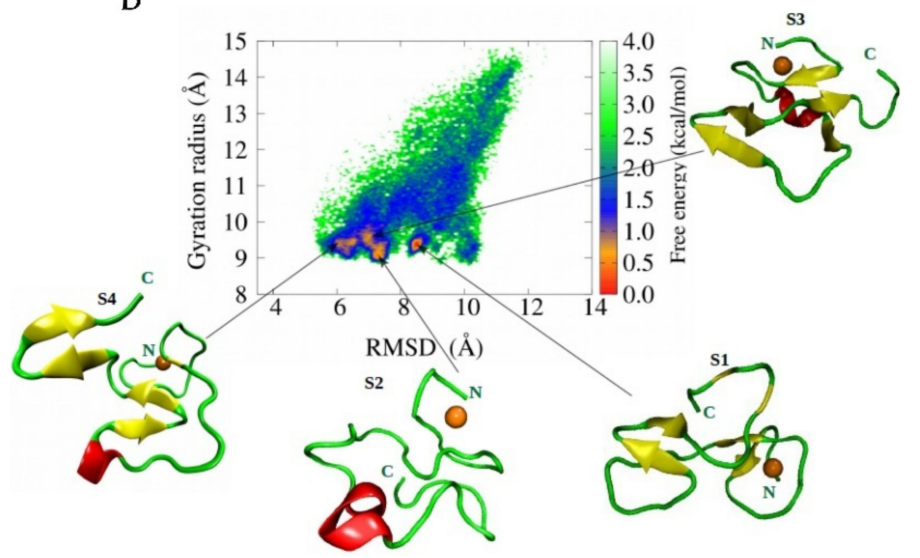

C
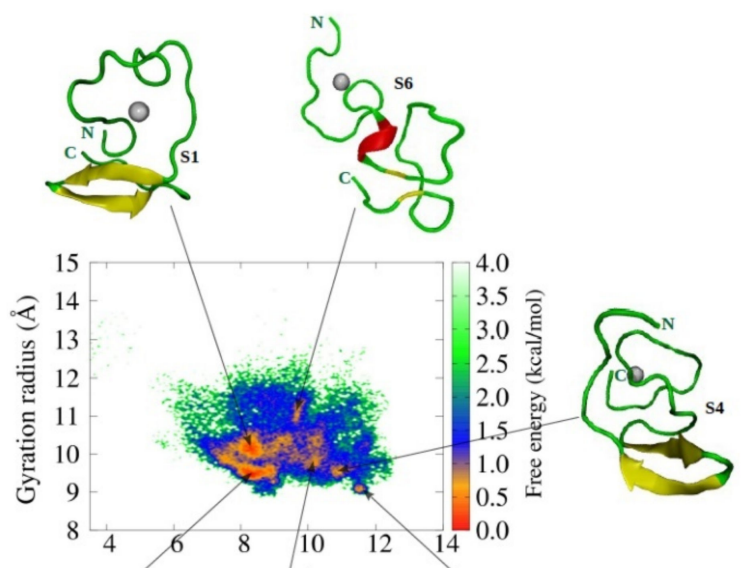

Figure 4. Free energy landscape for (A). A $\beta 42$, (B). A $\beta 42-\mathrm{Cu}^{2+}$, and (C). A $\beta 42-\mathrm{Zn}^{2+}$ peptides as a function of RMSD and the gyration of radius. Results are based on the whole ensemble of trajectories. Representative structures in the free energy minimum basins are displayed. Reproduced with permission from the work of Boopathi et al. [98]. Copyright 2020 John Wiley and Sons.

Lee et al. [100] performed MD simulations with the CHARMM27 force field and reported three significant insights: (a) $\mathrm{Zn}^{2+}$ ion mediated to increase the hydrogen bond network between $A \beta_{1-42}$ layers of the oligomers, which caused to reinforce the stabilization of $A \beta_{1-42}$ oligomers, in contrast, the same ion decreases the stabilization of $A \beta_{1-42}$ fibrils by reducing the hydrogen bond network, (b) in comparison to $\mathrm{Cu}^{2+}, \mathrm{Zn}^{2+}$ destabilizes $\mathrm{A} \beta_{1-42}$ fibrils more effectively, $\mathrm{Cu}^{2+}$ does not reduce the hydrogen bond network in the fibril and 
(c) in comparison to $\mathrm{Cu}^{2+}, \mathrm{Zn}^{2+}$ binding did significant attenuate the energy of the salt bridge, which is an essential role in the formation of $A \beta_{1-42}$ aggregation.

It is known that two residues are oxidized in $A \beta$, met35 is oxidized to a sulfoxide and Tyr10 is oxidized to form dityrosine covalent dimer; these oxidations impact the fibril formation. Met35 is oxidized by $\mathrm{H}_{2} \mathrm{O}_{2}$ alone without the presence of oxidation radicals. The oxidation of Tyr 10 by radicals to form a Dityrosine covalent $A \beta$ dimer has five- and eightfold higher concentration in the hippocampus and neocortical region of the AD brain [101]. $\mathrm{Cu}^{2+}$ has a higher concentration in the AD patient brain, and $\mathrm{H}_{2} \mathrm{O}_{2}$ commonly exists at physiologically and mild acidic conditions. Miao et al. [102] have curiously monitored the relation between the concentration of $\mathrm{Cu}^{2+}+\mathrm{H}_{2} \mathrm{O}_{2}$ and the amount of Dityrosine production by using experimental studies, noted $5 \mu \mathrm{m}$ of $\mathrm{Cu}^{2+}$ concentration and a higher concentration of $\mathrm{H}_{2} \mathrm{O}_{2}$ from $0.4 \mathrm{mM}$ to $1.6 \mathrm{mM}$ that can enhance the amount of Dityrosine formation. By contrast, they found that the total dityrosine production is not affected by two-fold higher concentration $\mathrm{Cu}^{2+}$ ions $(10 \mu \mathrm{m})$ with the same $\mathrm{H}_{2} \mathrm{O}_{2}$ concentration. These results supported $\mathrm{H}_{2} \mathrm{O}_{2}$ rather than $\mathrm{Cu}^{2+}$ as the main catalyzer in dityrosine productions. In addition, the $\mathrm{Cu}^{2+}+\mathrm{H}_{2} \mathrm{O}_{2}$ redox cycling system oxidized most of the monomers within $100 \mathrm{~h}$ to produce a Dityrosine dimer. This effect accelerates the preformed $\mathrm{A} \beta_{1-40}$ fibril formation and reduces fibril length from $800 \mathrm{~nm}$ to $150 \mathrm{~nm}$.

Santis et al. [103] utilized an X-ray Absorption spectroscopy to obtain the data for $\mathrm{A} \beta_{1-42}$ with $\mathrm{Cu}^{2+}$ and $\mathrm{Zn}^{2+}$ complex samples and reported that $\mathrm{Zn}^{2+}$ binding to $\mathrm{A} \beta_{1-42}$ could affect the $\mathrm{Cu}^{2+}$ coordination to the same peptide. If $\mathrm{Zn}^{2+}$ is added to the $\mathrm{A} \beta_{1-42}$ solution first, it prevents $\mathrm{Cu}^{2+}$ binding to the $A \beta_{1-42}$ peptide. In contrast, if $\mathrm{Cu}^{2+}$ is added first does not inhibit $Z n^{2+}$ binding to the $A \beta_{1-42}$ peptide.

In general, the $A \beta$ peptide could not adopt a unique conformation because of their disordered nature. Its binding to metal ions is quickly is equilibrated in an aqueous environment compared with wild-type A $\beta$ peptide. Srivastava et al. [104] answered the following fundamental question. Does metal ion affect the formation of aggregates and fibril formation? Of course, a high concentration of metal ions triggered fibril formation. For instance, $\mathrm{Zn}^{2+}$ and $\mathrm{Cu}^{2+}$ inhibit $\mathrm{A} \beta_{1-42}$ fibrillization and promote non-fibrillar aggregates. Later studies by Electron microscopy have shown that amorphous (non-fibrillar) aggregates convert into fibrils by binding metal ions. This result implies that amorphous aggregates are not the final point in the aggregation process. In other words, there are two cases, fibrils and small aggregation, for instance, metal ions are present in "amorphous" and "mature fibril" aggregates in which His6, His13, and His14 are coordinated with the metal ions. In particular, metal-bound His13 and His14 (beta-sheet conformation) side chains are found in opposite sides of the peptide. Later, the opposite trend followed by the small aggregation in which monomeric $A \beta$ binds to metal ions through H6, H13, H14 and amino acid terminus, but $\mathrm{H} 13$ and $\mathrm{H} 14$ not bound with metal ions on opposite sides of the peptide chains resulting in around $\mathrm{H} 13$ and $\mathrm{H} 14$ regions could not convert $\beta$-sheet conformation. In some cases, His6 also does not turn into a $\beta$-sheet conformation in most of the fibrils since metal ions mediate a lesser binding effect. We commented that high concentrations of metal ions could mediate the amorphous $A \beta$ aggregation, while low concentrations have triggered the $\mathrm{A} \beta$ fibril structure. It is noteworthy that the positive-charged metal ions can reduce the net-negative charge of $A \beta$, resulting in an enhancement of the aggregation rate of the peptide.

What metal ions induce $A \beta$ cytotoxicity?

A $\beta$ peptide can reduce $\mathrm{Cu}^{2+}$ to $\mathrm{Cu}^{+}$, and $\mathrm{Fe}^{3+}$ to $\mathrm{Fe}^{2+}$, facilitating the generation of reactive oxygen species $\mathrm{H}_{2} \mathrm{O}_{2}$ and $\mathrm{OH}^{\bullet}$ radical. Tyr10 residue of the $\mathrm{A} \beta$ peptide loses one electron and produces reactive tyrosine radicals, which bind to the peptide to form a dimer, causing the killing of the brain cells [105]. On the other hand, (a) metal ions can induce conformational changes and are more aggregation-prone structures than the monomeric $\mathrm{A} \beta$ peptide and (b) they can allow via molecular bridging the formation of aggregates.

To elucidate the role of Tyr10 residue on the $A \beta$ self-assembly mechanism, Coskuner and Uversky [106] have utilized AMBER FF14SB and CHARMM22/CMAP FFs, employed 
REMD (7.2 $\mu \mathrm{s})$ with thermodynamics calculation to study wild-type and Tyr10Ala mutation of $A \beta_{1-42}$ monomer in the explicit aqueous environment. They have observed two issues (a) Tyr10 residue promotes higher toxic $\beta$-sheet formation in the structural ensemble of $\mathrm{A} \beta_{1-42}$ monomer; however, (b) an opposite trend followed by Tyr10Ala mutation decreases the $\beta$-sheet formation in the monomer. In general, the $\beta$-sheet formation in the peptide plays a vital role in self-assembly and fibril formation. This result revealed that Tyr10 regulates the toxic $\beta$ sheet structure formation in the monomer causing faster self-assembly, but Tyr10Ala mutation impedes the self-assembly by decreasing the $\beta$ sheet content. An open question is the impact of Tyr10 in $A \beta$ in the presence of metal ions has not been elucidated yet.

Notably, the $\mathrm{Cu}^{2+}$ binding to $\mathrm{A} \beta$ generates less radial oxygen species in the case of murine than human $A \beta$, same in rats and mice that have not developed AD pathology because $A \beta$ contained a lack of His13, a crucial residue in the binding of metal ions. The His13 residue mutation in human Alzheimer's $A \beta$ peptide is one of the ongoing research fields [107-111].

\subsection{Fe Interaction with $A \beta$ Peptide}

So far, one study reported in the literature deals with $\mathrm{Fe}^{2+}$ interaction with $\mathrm{A} \beta$ peptide. We conducted $200 \mathrm{~ns}$ MD simulations with DFT study [112] to probe the structural dynamics of $A \beta_{1-42}-\mathrm{Zn}^{2+}, A \beta_{1-42}-\mathrm{Cu}^{2+}$ and $A \beta_{1-42}-\mathrm{Fe}^{2+}$. Our results suggested that $\mathrm{Fe}^{2+}$ binding generates a U-shaped structure in Lys16-Met35 with the turn in the loop region and $\beta$-sheet extended over central hydrophobic and C-terminal regions, which is corroborated by the NMR study $[76,113]$. Overall, this result implies that $\mathrm{Fe}^{2+}$ binding enhances the fibril aggregation of the $A \beta_{1-42}$.

\subsection{Al Interaction with A $\beta$ Peptide}

Matthew Turner et al. [114] have employed five-microsecond MD simulation with AMBER ff14SB forcefield and study the process of how $\mathrm{Al}^{3+}$ governs the structural dynamic behaviour of $A \beta_{1-40}$ and $A \beta_{1-42}$ peptides. They observed $A l^{3+}$ forming robust coordination with negatively charged E3, D7 and E11 residues, with coordination number of four. Such coordination persisted throughout the simulations despite metal ion bindings being modeled as a non-bonded model. This description has significantly impacted the structure and dynamics of both $A \beta_{1-40}$ and $A \beta_{1-42}$ peptides changes by promoting the helical structure formation by severely disrupting the salt-bridge network. Surprisingly, why is $\mathrm{Al}^{3+}-\mathrm{A} \beta$ binding coordination not disrupted throughout the simulation, even though a non-bonded metal binding model describes it? It is yet unclear. Is it an artifact of the chosen force field or simulation protocol that maintains the metal coordination? In this connection, Platts [115] utilized the semi-empirical tight-binding method GFN2-XTB for modelling the interaction of $\mathrm{Al}^{3+}$ with truncated $\mathrm{A} \beta_{1-16}$ peptide; the outcome of the optimized geometry is in agreement with DFT benchmark data. Metadynamics simulation has been used to explore exhaustively the coordination pattern of the same peptide [115]. The studies show that $\mathrm{Al}^{3+}$ binding to the $A \beta_{1-16}$ is highly fluxional due to all acidic sidechains and several backbone oxygens involving coordination. The estimated coordination number on average is 5.2 atoms per ion. This evidence confirmed that the metadynamics approach does not match the microsecond MD simulation regarding the metal coordination number. The main reason is that in the case of non-bonded, atomic FFs could neglect charge transfer and polarization for peptide-ion interaction. In the bonded approach, atomic charges are obtained based on electrostatic potential (RESP) derived by B3LYP/6-31G (d) level of theory, amino acid backbone of oxygen to $\mathrm{Al}^{3+}$ is more electronegative -0.79 e as compared with MD simulations of non-bonded counterparts -0.40 to 0.58 e. These differences lead metadynamics to promote higher coordination number (5.2) than molecular dynamics coordination number $(\sim 4)$. MD simulation permits conformational changes of the $\mathrm{A} \beta$ without disrupting metal coordination, while metadynamics accounts for the different metal coordination mode. 
Roldán-Martín et al. [116] have examined the structural features of $A \beta_{1-42}$ peptide upon $\mathrm{Cu}^{2+}$ and $\mathrm{Al}^{3+}$ binding by using Gaussian accelerated MD simulation with AMBER FF14SB force field. They noted the following: (a) $\mathrm{Cu}^{2+}$ binding increased $\alpha$-helical content in the $A \beta_{1-42}$ peptide causes U-shaped conformations which is promoted by Glu22/Asp23Ser26/Lys28 turn region that links two helices and arranges them in parallel through interhelical hydrophobic contacts, (b) by contrast, $\mathrm{Al}^{3+}$ binding can convert the helical contents into the extended structure, which are more favourable for $\beta$-sheet formation, in other words, presence of $\mathrm{Al}^{3+}$ could have manifested aggregation-prone $\mathrm{A} \beta_{1-42}$ structures, and (c) the total charge of $A \beta_{1-42}$ is neutralized by +3 charge of $A l^{3+}$ metal, $A \beta_{1-42}-\mathrm{Al}^{3+}$ complex becomes zero total charge, and the complex accelerates their aggregation propensity faster as compared to $A \beta_{1-42}-C u^{2+}$ (charge, -1$)$ and $A \beta_{1-42}$ (charge, -3 ).

\subsection{Ag Interaction with $A \beta$ Peptide}

Wallin et al. [117] used Fluorescence spectroscopy, solid-state AFM imaging, circular dichroism spectroscopy, and NMR spectroscopy to probe the A $\beta$ fibrillization pathways in the presence of silver $\left(\mathrm{Ag}^{+}\right)$metal ions. The $\mathrm{A} \beta$ peptide from the fibril incorporates other monomeric $\mathrm{A} \beta$ to elongate the fibril end. The $\mathrm{Ag}^{+}$ion made weak binding to the $N$-terminal of the monomeric $A \beta$ that lead to weakens the $A \beta$ fibrillization kinetics by reducing fibril end elongation rate. Therefore, $\mathrm{Ag}^{+}$bound peptide is insufficient of maintaining aggregation by decreasing the $A \beta$ for fibril extension and the same observation is applied by the case $\mathrm{Zn}^{2+}$ binding with the $\mathrm{A} \beta$ peptide. These systems confirmed $\mathrm{Ag}^{+}$ crucial role in suffering the bulk aggregation by retardation of the fibril end elongation.

\section{5. $\mathrm{Pb}$ Interaction with $A \beta$ Peptide}

The NMR studies confirmed the presence of $\mathrm{Pb}$ in the AD brain, this molecule induces an increase in the concentration of $A \beta$ in rats [118] and enhances plaque formation in monkeys [119]. Wallin et al. [120] inspect the impact of the metal ions $\mathrm{Cd}^{+}, \mathrm{Cr}^{2+}, \mathrm{Pb}^{2+}$ and $\mathrm{Pb}^{4+}$ on $\mathrm{A} \beta$ aggregation by employed experimental studies. They found a couple of significant observations such as: (a) $\mathrm{Pb}^{4+}$ binds $\mathrm{H6}, \mathrm{Y} 10, \mathrm{E} 11, \mathrm{H} 13$, and $\mathrm{H} 14$ residues of $\mathrm{A} \beta_{1-40}$ monomer and it can mediate faster aggregation rate, as compared with $\mathrm{Cd}^{+}, \mathrm{Cr}^{2+}$, and $\mathrm{Pb}^{2+}$ metal ions, which typically establishes electrostatic interaction with a monomer. The NMR and Fluorescence spectroscopy showed that $\mathrm{Pb}^{4+}$ binding to $\mathrm{A} \beta$ is slightly different from the $\mathrm{Cu}^{2+}$ and $\mathrm{Zn}^{2+}$ binding residues of $\mathrm{D} 1, \mathrm{H} 6, \mathrm{H} 13$, and $\mathrm{H} 14,(\mathrm{~b}) \mathrm{Pb}^{4+}$ binding induces M35 residue oxidation, facilitating the release of harmful reactive oxygen species (ROS) in the plaques that damage the neuron activities.

\subsection{Hg Interaction with $A \beta$ Peptide}

Most humans are exposed to mercury by eating fish and shellfish contaminated with methylmercury. In general, $\mathrm{Hg} 2+$ ions cannot pass the blood-brain barrier (BBB), but metallic vapor mercury penetrated $\mathrm{BBB}$ to oxidized $\mathrm{Hg}^{2+}$ trapped inside the brain. Early studies [121] suggested the $\mathrm{Hg}^{2+}$ binds to thiol(-SH) and selenohydryl (-SeH) groups contained residue only. Thus, it does not bind the $\mathrm{A} \beta_{1-42}$ peptide because cysteine residues are absent. Nevertheless, recent experiments reported [122] $\mathrm{Hg}^{2+}$ directly interacting with $\mathrm{A} \beta$ peptide and strengthen the hypothesis of $\mathrm{Hg}^{2+}$ risk factor in AD. Subsequently, the molecular interaction of the $\mathrm{A} \beta_{1-42}$ with $\mathrm{Hg}^{2+}$ [123] has been explored using NMR, Fluorescence Spectroscopy and AFM, the outcome implies that $\mathrm{Hg}^{2+}$ binds to $\mathrm{H6}, \mathrm{H} 13$, and $H 14$ which can impede the $A \beta_{1-40}$ and $A \beta_{1-42}$ fibrillization and facilitate amorphous aggregation at a $1: 1 \mathrm{Hg}^{2+} / \mathrm{A} \beta$ ratio.

\subsection{Mn Interaction with $A \beta$ Peptide}

Several AD symptoms appear suddenly after severely exposed manganese [124], the relationship between $\mathrm{Mn}$ and AD is an ongoing debate. Wallin et al. [125] have used NMR, $\mathrm{CD}, \mathrm{AFM}$, Fluorescence spectroscopy and MD simulation to monitor the effect of $\mathrm{Mn}^{2+}$ ions on $A \beta$ aggregation and fibrils. The NMR data [126] reported that $A \beta_{1-16}-\mathrm{Zn}^{2+}$ complex 
with $\mathrm{Zn}^{2+}$ is coordinated by $\mathrm{H} 6, \mathrm{H} 13, \mathrm{H} 14$, and E11 residues. When $\mathrm{Zn}^{2+}$ manually was replaced by $\mathrm{Mn}^{2+}$ in the same complex and modelled $\mathrm{A} \beta_{1-16}-\mathrm{Mn}^{2+}$ complex with Mn2+ binds result in similar binding to the same residues: H6, H13, H14, and E11. This complex was used treated as an input structure for microsecond MD simulations. During MD simulation, the $\mathrm{Mn}^{2+}$ dissociated from initial binding residues, as it preferred to coordinate negatively charged residues of D1, E3, D7, and E11. These amino acids prevent the His residue from binding $\mathrm{Mn}^{2+}$ ion.

Consequently, NMR data proved that D1, H13, D22, and E23 residues are more favourable for $\mathrm{Mn}^{2+}$ binding. Simulations and experiments predicted different binding sites for $\mathrm{Mn}^{2+}$, the exact details of $\mathrm{Mn}^{2+}$ coordination mode are still under investigation. Furthermore, CD spectroscopy and THT fluorescence data imply random coil (in the starting structure of $A \beta$ peptide) transitions to $\beta$-sheets. In addition, the AFM image showed $A \beta_{40}$ peptide aggregation mediates the formation of fibril structures, but $\mathrm{Mn}^{2+}$ does not influence at all on aggregation kinetics and fibril morphology of $A \beta_{40}$ due to the weak interaction with the peptide. However, more simulations are required to model truncated $A \beta_{1-16}$ or the full length of $A \beta$ bound to $\mathrm{Mn}^{2+}$ ions.

Geng Lin et al. [127] have tested eight-month-old male mice divided into Mn-treated mice and controlled mice groups. Mn concentration was measured using mass spectroscopy at the end of the fifth-month treatment. The measurement ensured Mn level in similar concentration in blood and the brain. The qRT-PCR and western blot analysis confirmed in the case of $\mathrm{Mn}$-treatment increased $\beta$ - and $\gamma$-secretases cleavages at APP, an enormous amount of $A \beta_{1-42}$ peptides production in the cerebral cortex and hippocampus of brains, while $\alpha$-secretase cleavage activity was significantly reduced. These data suggested that $\mathrm{Mn}$-treatment is a risk factor for the development of AD pathogenesis. However, no studies in the literature reported the effect of $\mathrm{Mn}$ on $\mathrm{A} \beta_{1-42}$ productions at atomic level details. The beforementioned studies supported the $\mathrm{A} \beta$ aggregation modified by $\mathrm{Fe}^{2+}, \mathrm{Mn}^{2+}, \mathrm{Pb}^{4+}$ and $\mathrm{Zn}^{2+}$, as well as the $\mathrm{Hg}^{2+}$ binding to specific residues of the $\mathrm{A} \beta$ peptide.

\subsection{Li Interaction with $A \beta$ Peptide}

The AD symptoms are significantly reduced by the $\mathrm{Li}^{+}$ions treatment $[57,128,129]$, which showed a substantial improvement regarding $A \beta$ clearance [130], enhance spatial memory [131], reduced oxidative stress level [132] and decreased the amount of $A \beta$ plaques [133] in AD brain. Berntsson et al. [134] used biophysical techniques, NMR, Fluorescence quenching, $\mathrm{CD}$, and IR, to monitor the elusive in vitro interaction between $\mathrm{Li}^{+}$ and $A \beta$ peptide. They found that $\mathrm{Li}^{+}$displayed weak interaction with the $A \beta$, resulting in unaltered secondary structures of $A \beta_{1-40}$ monomers and $A \beta_{1-42}$ oligomers. At elevated $\mathrm{Li}^{+}$concentration, $\mathrm{Li}^{+}$can manifest minor perturbation-effect on the morphology of aggregated $A \beta_{1-40}$ fibril, $A \beta_{1-40}$ aggregation kinetics and $A \beta_{1-42}$ oligomeric stability. Overall, the results suggested $\mathrm{Li}^{+}$ions are not able to modulate the $A \beta$ aggregation and toxicity. The $\mathrm{Li}^{+}$treatment on $\mathrm{AD}$ progression is not caused by direct interaction of $\mathrm{Li}^{+}$with $\mathrm{A} \beta$.

\section{What Is the Role of Small Molecules in Inhibition Mechanism of A $\beta$ Aggregation?}

Researchers have widely used four novel therapeutic approaches to reduce plaque formation, (a) secretase inhibitors and modulators, (b) immunotherapeutic strategies, (c) peptide-based inhibitors, and (d) small molecular inhibitors.

\subsection{Secretase Inhibitors and Modulators}

Preventing the $A \beta$ production by inhibiting the activity of $\beta$ - and $\gamma$-secretase at APP has been a frontier biomedical research for AD treatment. In this account, Astra and Eli Lilly [135] have identified AZD3293 inhibitors that block the APP cleaved by $\beta$-secretase. Subsequently, several $\beta$-secretase inhibitors (OM99-2, KMI-429, GSK188909, 4-phenoxypyrrolidine, GRL-8234 and CTS-21166) were shown to attenuate plaque formation in the mice brain effectively [136]. The six $\gamma$-secretase inhibitors (DAPT, PF-3084014, LY-450139, BMS-708163, MPC-7869 and Begacestat) (Figure 5) have reached the clinical 
trial [136-138]. In 2001, an in-vivo study demonstrated for the first time that $\gamma$-secretase inhibitor DAPT ( $\mathrm{N}$-[N-(3,5-difluorophenacetyl)- 1-alanyl]-S-phenylglycine t-butyl ester) blocked the $\mathrm{A} \beta$ production in the AD mice brain, but the lymphocyte development and the intestine symptoms were still observed [138]. During the prenatal period, Lymphocyte development occurs in humans. The new-born immune system contains functional $\mathrm{T}$ (thymus-derived) and B (born-marrow derived) lymphocytes. T and B lymphocytes are responsible for the function of antibody production and cell-mediated immune responses, respectively. Symptoms of intestine problems are stomach pain, vomiting, nausea, dehydration, a feeling of illness, and difficulty passing gas.

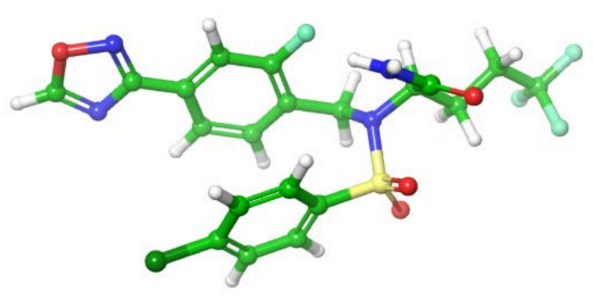

BMS-708163

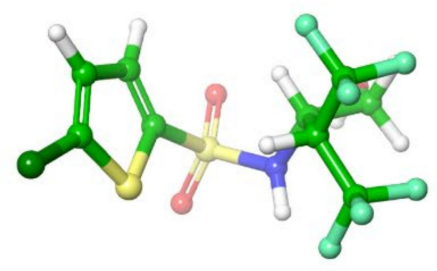

GSI-953
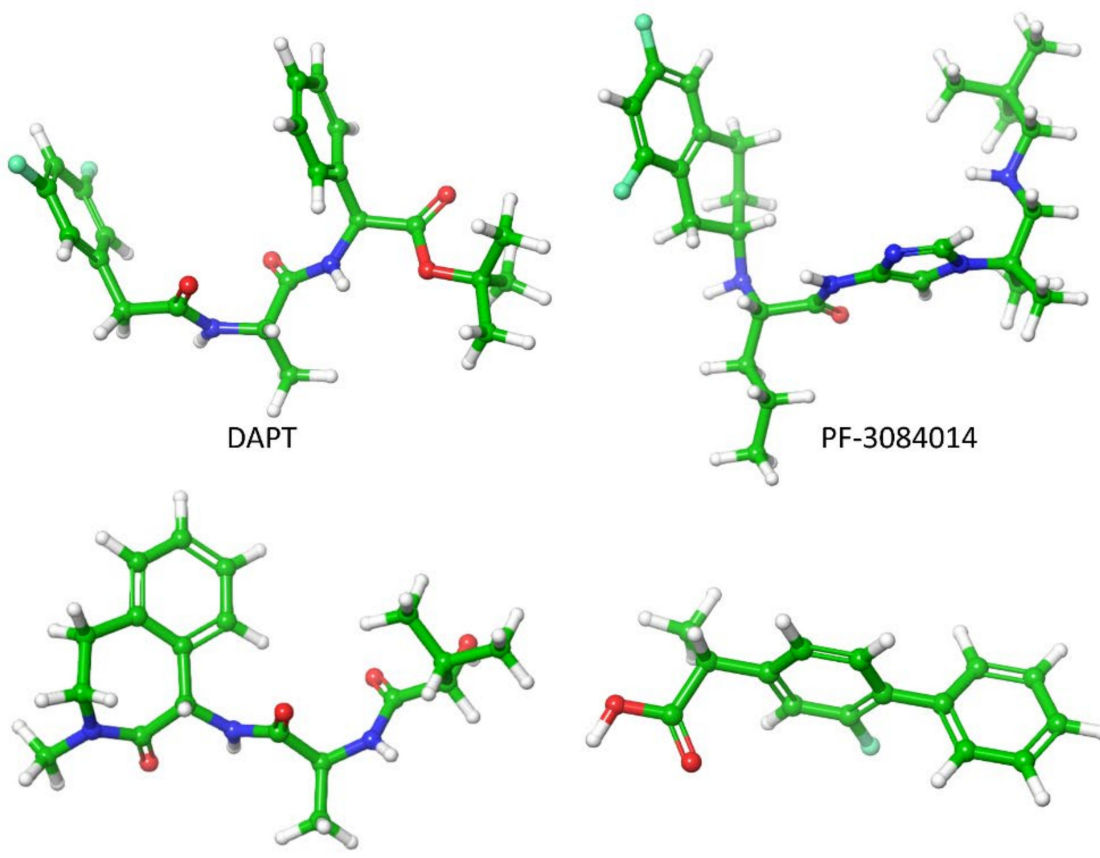

LY-450139

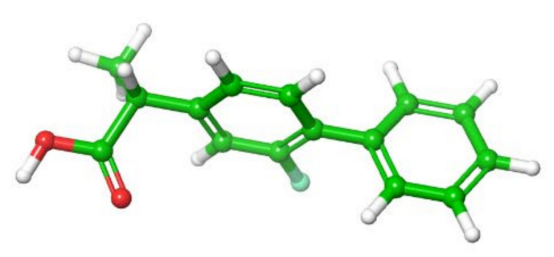

LY-450139

Figure 5. The $\gamma$-secretase inhibitors used in clinical trial for the treatment of AD and taken from PubChem.

The PF-3084014 (Nirogacestat) has significantly reduced the A $\beta$ level in the brain, plasma and cerebrospinal fluid in guinea pigs and Tg2576 transgenic mice. Since it was linked to a highly lipophilic nature, the clinical trial was discontinued due to an unfavorable pharmacokinetic and pharmacodynamic profile. The avagacestat (BMS-708163) significantly reduces $A \beta_{1-40}$ levels in female rats, and significantly reduce $A \beta_{1-40}$ in the brain and cerebrospinal fluid (CSF) of male beagle dogs [139]. The semagacestat (LY-450139) could reduce the plasma $\mathrm{A} \beta_{40}$ concentration by $58 \%$ and $65 \%$ for the $100-\mathrm{mg}$ and $140-\mathrm{mg}$ groups, respectively [140]. The avagacestat and semagacestat inhibitors blocked $\gamma$-secretase activity at APP in the cell membrane. However, these inhibitors failed in a phase 2 and phase 3 of clinical trials because they generated a degeneration in cognitive ability in $\mathrm{AD}$ patients along with other severe side effects.

During the semagacestat treatment, side effects were shown to increase the risk of skin cancer. Begacestat (GSI-953) decreased A $\beta$ levels in plasma, brain, and cerebrospinal fluid in Tg2576 mice, but it failed to reduce $A \beta$ concentration in the $A D$ patient brain [141]. It was discontinued in the phase 1 trial in 2010. Tarenflurbil (MPC-7869) produced A $\beta 38$ instead of A $\beta 42$ by modifying the $\gamma$-secretase at APP. The A $\beta 38$ manifested lower neurotoxicity and phase 2 trials showed encouraging results. The Phase 3 trial terminated in 2009 since the agent penetrate the blood-brain barrier insufficiently [137]. However, those inhibitors have decreased $A \beta$ concentrations in the animal brain, but they showed severe side effects in $\mathrm{AD}$ patients. 


\subsection{Immunotherapeutic Strategies}

In the immunotherapeutic approach, immunotherapy induces the host cell to recognize and fight $A \beta$ in order to reduce $A \beta$ aggregation in the brain. It is divided into two categories (a) active immunization and (b) passive immunization. The primary is to generate a vaccine for $A \beta$ production to reduce plaques. The latter is to produce monoclonal antibodies and administration of immunoglobulins. The following five drug candidates, bapineuzumab, solanezumab, gantenerumab, aducanumab and Lecanemab, are humanized monoclonal antibodies except for solanezumab, which is another monoclonal antibody [142-144]. The first four drugs have significantly improved cognitive abilities and are undergoing clinical phase 2 or 3 trials, while Lecanemab binds soluble $\mathrm{A} \beta$ and potential diseases attenuated by removing plaques.

The monomers, oligomers and fibrils of $\mathrm{A} \beta$ have exposed epitopes; typically, they are the same and antibodies can recognize and bind the epitopes of $A \beta$. Muller et al. [145] revealed that 20 amino acid SDPM1 proteins bind to the structure of the tetramers of $\mathrm{A} \beta 40$ and $\mathrm{A} \beta 42$ peptides, blocking $\mathrm{A} \beta$ association and removing plaques in $\mathrm{AD}$ brain. Solanezumab, Gantenerumab, and IVIG antibodies can improve cognitive skills by binding soluble $A \beta$ peptides in the clinical trial $[146,147]$. The solanezumab and crenezumab have higher contact with the $A \beta$ via KLVFF epitope [148]. The human anti-A $\beta$ monoclonal antibody, gantenerumab, crossed the blood-brain barrier, binding aggregates of $A \beta$ through the $\mathrm{N}$-terminal and central regions of the peptide resulting in a removal of $\mathrm{A} \beta$ plaques, which was observed in phase 3 clinical study [143].

The drugs mainly target amyloid peptide, tau protein, mitochondrial dysfunction, oxidation stress and metal dysregulation to reverse the AD progression. Although a good amount (approximately 111 drugs) of drug candidates released between 2010 and 2020 [136], the majority of the candidates failed in phase 2 trials primarily due to the lack of the ability to reduce toxicity, cognitive loss and plaques formation, and more than 50 candidates reached phase 3 trial. $40 \%$ of the candidates fell into repurposed drugs. Notably, the four repurpose drugs, escitalopram, brexipiperazole, masitinib, and losartan, are undergoing phase 3 clinical trials. However, today, only one drug, aducanumab, successfully passed the phase 3 clinical trial and came to the market for mild AD patient's treatment.

The FDA approved two types of drugs (Figure 6A-D): (a) cholinesterase inhibitors and (b) memantine [1]. The primary can boost the amount of cholinesterase, which is responsible for memory functions. The latter inhibitor regulates the activity of glutamate, which is a messenger chemical involved in brain function, including learning and memory. There are three cholinesterase inhibitors: Donepezil (Aricept), Galantamine (Razadyne), and Rivastigmine (Exelon). Donepezil is used in all stages of AD patients, Galantamine serves to treat mild to moderate disease, and Rivastigmine in case of severe AD patients. These inhibitors reduce the symptoms of the disease with side effects including nausea, vomiting and diarrhea. Thus, these therapeutics can alleviate some of AD symptoms, but not the course of the disease. 


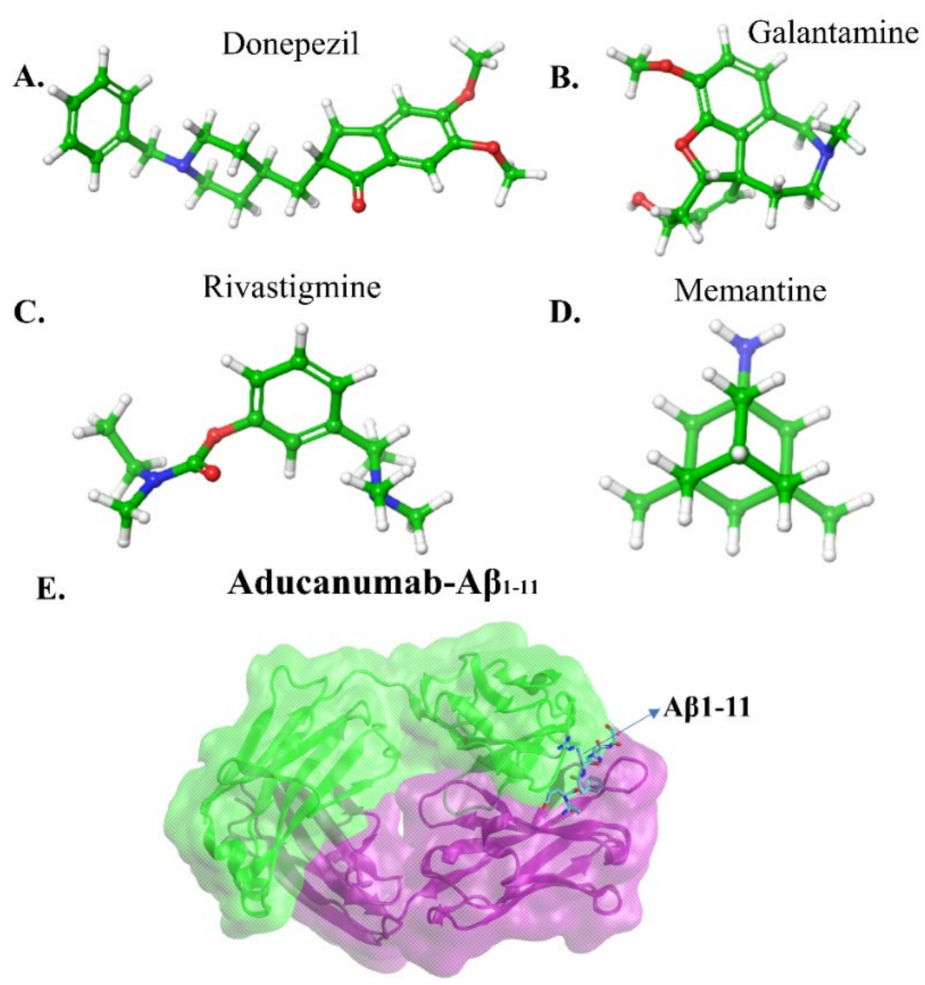

Figure 6. The U.S FDA approved drugs for AD (A) Donepezil, (B) Galantamine, (C) Rivastigmine and (D) Memantine. (E) fragment antigen-binding region of aducanumab (AduFab) -A $\beta_{1-11}$ peptide. AduFab depicted by van-der-Waals surface. The chemical structures taken from PubChem and protein data bank.

In this perspective, Sevigny et al. [11] utilized positron emission tomography (PET) to monitor the efficacy of an aducanumab in mice and human brains. Aducanumab (Figure 6E) is an IgG1 monoclonal antibody and recombinant antibody derived from slow or absent cognitive decline patients. Three separated patient groups were subjected in this study, double-blind, randomized and placebo-controlled. The patients were clinically diagnosed with mild $\mathrm{AD}$, and 1, 3, 6 and $10 \mathrm{mg} \mathrm{kg}^{-1}$ doses of aducanumab were given to $31,32,30$ and 32 patients respectively for one year. In the end, the result was compared with the placebo-controlled group (40 patients). The PET measurement showed that the $\mathrm{A} \beta$ plaques formation has significantly reduced in subcortical white matter and cortical regions of the brain at 6 and $10 \mathrm{mg} \mathrm{kg}^{-1}$ within 54 weeks. In the placebo-controlled cases, no changes occurred at amyloid plaques. In addition, they gave $0.3,1,3,10$ and $30 \mathrm{mg} \mathrm{kg}^{-1}$ doses to mice for 9.5 to 15.5 months and discovered that $63 \%$ of $\mathrm{A} \beta$ plaques in the cortex and hippocampus of mice brains disappeared at 10 or $30 \mathrm{mg} \mathrm{kg}^{-1}$ doses. This evidence supports the strong effect of aducanumab entering the brain and reducing plaque formation by binding with the $A \beta$. All the data revealed aducanumab as a potential inhibitor for disease-modifying by decreasing soluble and insoluble $A \beta[149,150]$. Due to the removal of rich amyloid plaques and minimizing side effects, a milestone in AD therapy occurred on June 7th, 2021, the U.S. FDA approved aducanumab for the AD treatment [151].

Arndt et al. [152] deposited a crystal structure of AduFab (the fragment antigenbinding region of aducanumab)-A $\beta 1-11$ peptide complex in the protein data bank (PDB id:6co3). In this structure, aducanumab binds to 3-7 residues of $A \beta$ in an extended conformation. Furthermore, Frost and Zacharias [153] have performed MD simulation to explore the interaction between AduFab and A $\beta 1-40$ peptide in the form of monomers, dimers, oligomers, and fibrils. The result suggested that AduFab binding affinity is increased in oligomers and fibrils compared to monomers. 


\subsection{Peptide-Based Inhibitors}

Calcium ions flow in the membrane to increase the release of synaptic vesicles in hippocampal neurons that generate neurotransmission. In contrast, the $\mathrm{A} \beta$ plays a role in decreasing the number of synaptic vesicles that cause neurotransmission failure. Subsequently, the $\mathrm{A} \beta$ oligomer directly interacts with the membrane generating pore structure in which the flow of calcium is increased and leads to cell death. In this connection, Peter et al. [154] derived pentapeptide $\left(\mathrm{G}_{33} \mathrm{LMVG}_{37}\right)$ from the glycine zipper region of Cterminal $A \beta$. Experiments characterized the $A \beta$ activity upon the pentapeptide interaction, which confirmed $\mathrm{G}_{33} \mathrm{LMVG}_{37}$ involvement in three main activities: (a) blocking the increase of the calcium level in the neurons (b) inhibiting the perforation in the membrane (c) preventing the association of $A \beta$ peptide. Finally, this pentapeptide supports neurotransmission by blocked $A \beta$ induced membrane pore formation. In other words, the small size of the hydrophobic entity crosses the blood-brain barrier to reduce plaque formation. Other pentapeptides, $\mathrm{G}_{25} \mathrm{SNKG}_{29}$ and $\mathrm{G}_{29} \mathrm{AIIG}_{33}$, could not have any effect on $\mathrm{A} \beta$ peptide aggregation.

Zheng et al. [155] have employed multiple approaches such as ion mobility spectroscopy, mass spectroscopy, and MD simulation to characterize the interaction between the full length $A \beta_{1-42}$ and two modified $A \beta_{39-42}$ derivatives: VVIA-NH2 and Ac-VVIA. The mass spectroscopy revealed VVIA-NH2 binding to $A \beta_{1-42}$ monomers, dimers, tetramers, hexamers, or oligomers, while Ac-VVIA only binds to monomers. Ion-mobility spectroscopy results showed that VVIA-NH2 prevents dodecamers formation and generates non-toxic oligomers, which form fibrils. On the other hand, Ac-VVIA mediated toxic oligomers eventually led to a fibril. MD simulation results suggested VVIA-NH2 has a weak binding affinity to the C-terminal region of monomers. In contrast, Ac-VVIA showed a strong binding effect to multiple regions of $A \beta 1-42$. Overall, this data supported Ac-VVIA binding to oligomers as a crucial step for the inhibition of A $\beta 1-42$ toxicity.

\subsection{Small Molecular Inhibitors}

Drug repositioning and repurposing are promising therapeutic strategies for drug discovery of anti-AD. Cramer et al. [156] have demonstrated that the anti-cancer drug, bexarotene, it can reduce $50 \% \mathrm{~A} \beta$ plaques in mice models of $\mathrm{AD}$ within $72 \mathrm{~h}$. The following question is obscure: bexarotene destroys plaques by a direct interaction with $\mathrm{A} \beta$. In this account, In this account, Pham et al. [157] employed in-silico and in-vitro experiments to inspect the role of bexarotene in the $A \beta$ aggregation and reported that bexarotene showed week interaction affinity to $A \beta$ fibril, which does not affect amyloid aggregation. The $A \beta$ produced by the cleavage of APP by $\beta$ - and $\gamma$-secretase, whose activity is tuned by the drug that is ongoing research to remove plaque formation. Subsequently, they also used in-silico and in-vitro experiments [158] to explore the possibility of preventing the $A \beta$ association by bexarotene binding to $\beta$-secretase. The results imply that plaques could not be reduced due to the weak interaction between $\beta$-secretase and bexarotene. However, one more possible investigation remains obscure, examining the interaction mechanism between $\gamma$-secretase and bexarotene to understand the reduction of plaques.

Mei et al. [159] have addressed the following question: How will the interaction between either negatively charged (ER) or neutral TS0/TS1 small molecules and A $\beta 42$ oligomers affect the aggregation of oligomers? They have identified, in a comparative study with a small neutral molecule, ER (charged -2), as a suitable candidate to inhibit the neurotoxicity of $A \beta_{42}$ aggregates through strong binding, decreasing aggregates hydrophobicity, degrading the $\beta$ sheet contents and inter-and intra-molecular hydrogen bond on the main chain, and perturbation of K23-L28 salt bridges and the vdW interactions. Hence, they recommend developing negatively charged inhibitors for the target $\mathrm{A} \beta 42$ oligomers to prevent plaque formation.

As shown in Figure 7, the intrinsically disordered A $\beta$ aggregation pathway has been characterized into four types [160]: (a) Primary nucleation, oligomers formed from monomeric species; (b) Elongation, oligomers and fibrils size increased by adding monomers; 
(c) Fragmentation, fibrils break into several oligomers and small fibrils that are capable of elongation; (d) Secondary nucleation, the surface of fibril aggregates promoting a new formation of oligomers species. Heller et al. [161] identified a small molecule, 10074g5 (biphenyl-2-yl-(7-nitro-benzo [1,2,5] oxadiazol-4-yl)-amine), which interacts with the monomeric state of $A \beta_{1-42}$ peptide using experiments, computational simulation and mathematical modelling. They observed (a) this molecule binds to monomeric $A \beta_{1-42}$ peptide resulting in a significantly delayed the primary- and secondary-nucleation pathways in $A \beta_{1-42}$ aggregation, (b) this molecule can decrease the hydrophobicity of the $A \beta_{1-42}$ peptide and c) this molecule inhibits the formation of the $A \beta_{1-42}$ association and toxicity by enhancing the conformation entropy.

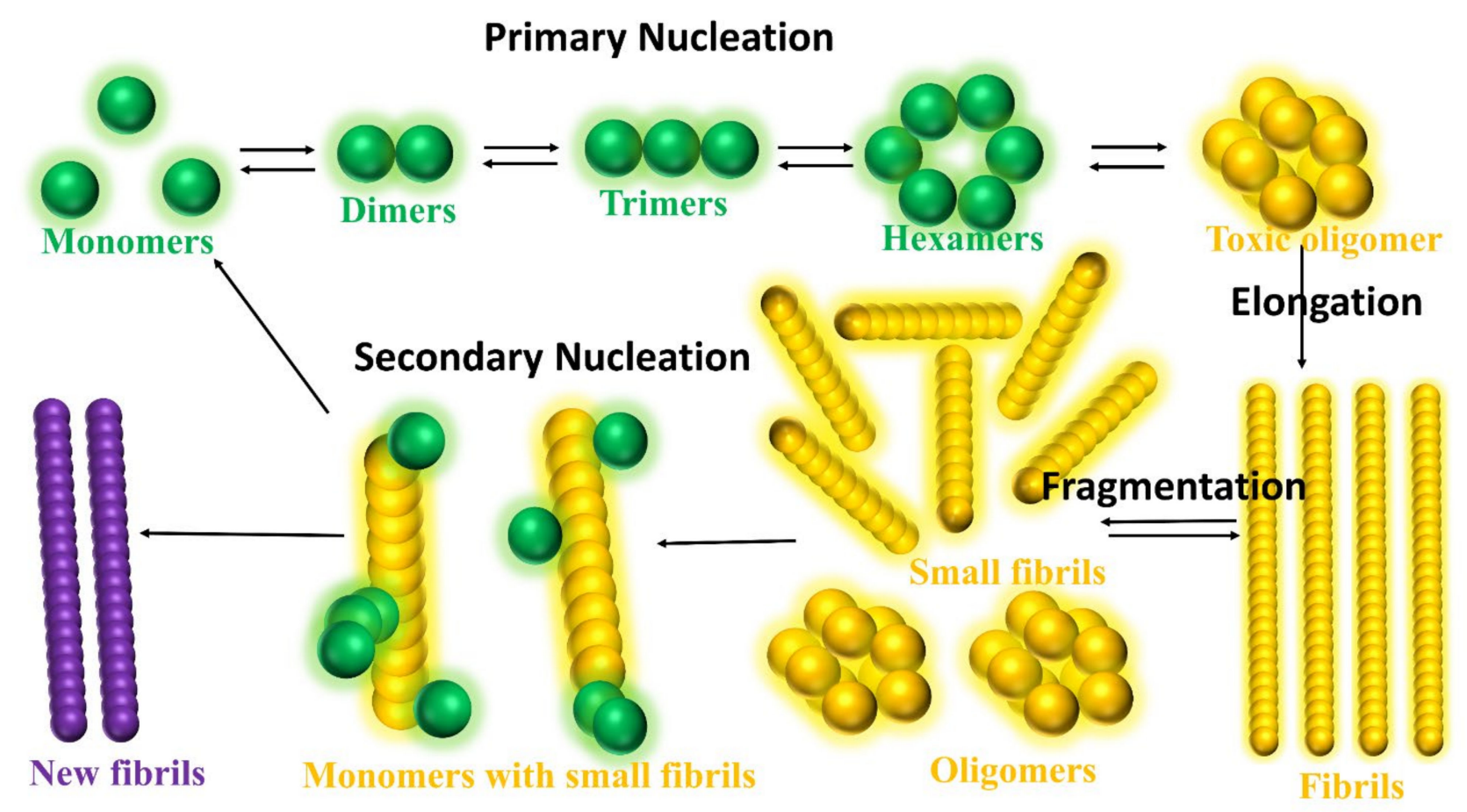

Figure 7. Schematic illustration of the aggregation pathways. There are characterized into four types: Primary nucleation, monomers formed dimers, trimers, hexamers and then oligomers. Elongation, the oligomers are joined together to generated the fibrils. Fragmentations, the fibrils break into the number of small fibrils and oligomers. Secondary nucleation, only minority of small fibrils convert into a new fibril by adding monomers, but due to the addition of monomers, the majority of the small fibrils turn into the monomers or oligomers.

Pagano et al. [162] have reviewed the role of the natural compound in the A $\beta$ peptide aggregation pathways using in-silico and in-vitro studies. The thirteen compounds (Brazilin, Curcumin, Epigallocatechin gallate, Ginnalin A, wgx-50, Myricetin, Oleuropein, Oleuropein aglycone, Reserveratol, Rosmarinic acid, Sclerotiorin, Tanshinone and Uncarinic acid C) were extracted from plants and observed that they cross the blood-brain-barrier. Since the solvent exposure of the hydrophobic surface is regulated $A \beta$ toxicity, inhibiting or modulating the toxicity of $A \beta$ aggregation is one of the main approaches against AD. Considerable evidence coming from the experiments and computer simulations have confirmed that those thirteen compounds can directly interact with $A \beta$ affecting amyloid aggregation pathway by (a) inhibiting formation of oligomers from monomers, (b) preventing the secondary nucleation of aggregation and (c) reducing the toxicity of aggregates.

Using REMD simulations, Mohamoudinobar et al. [163] have characterized the effect of $\mathrm{NaCl}$, scylloinositol and 4-aminophenol in $\mathrm{A} \beta_{1-42}$ aggregation pathway in an aqueous environment. In the case of pure water, $\beta$-sheet is formed in the residue segments $16-$ 22 (central hydrophobic region), 23-29 (central hydrophilic region) and the N-terminus, 
whereas in the case of $\mathrm{NaCl}$ contained water, the $\beta$-sheet is formed at $\mathrm{N}$ - and $\mathrm{C}$-terminal, but the $\beta$-sheet formation in the central hydrophilic region is inhibited. Furthermore, in pure water, frequent residue contacts have been observed between the central hydrophobic and the C-terminus which were reduced by increasing the interaction between C-terminus and central hydrophilic region in the presence of inhibitors (scylloinositol and 4-aminophenol). $A \beta_{1-42}$ peptide adopted a U-shaped conformation with strand-loop-strand structure in $\mathrm{NaCl}$ and pure water, but not in water-containing inhibitors. The U-shaped structure is well corroborated with the NMR fibril structure [164] and promotes $A \beta_{1-42}$ aggregates. This result implies that the inhibitors prevent the $A \beta_{1-42}$ aggregates, in contrast to the $\mathrm{NaCl}$ case.

In the past ten years of our research investigations, we have reached four main conclusions using in-silico, in-vitro and in-vivo experiments. (1) Nicotine molecule interaction causes the $\beta$-sheet of $A \beta$ transformation into the alpha-helical structure that prohibits the aggregation of $A \beta$ peptides [165]. (2) A venom of black mamba snake could inhibit the fibril formation of $\mathrm{A} \beta$ peptides by destroying the inter-peptide Asp23-Lys28 salt-bridge [166]. (3) U.S. FDA approved drug, gabapentin (GBP), binding to $A \beta_{1-42}$ peptides and blocked multiple actions: aggregation, oligomers toxicity, membrane poration, intracellular calcium and synaptotoxicity induced by $A \beta_{1-42}$ [167]. We recommend evaluating the GBP in a clinical trial for mild AD patients with a low dose of $400 \mathrm{mg} /$ day to avoid risk associated with higher doses. (4) We identified a new low molecular weight compound M30 (2-Octahydroisoquinoline-2 $(1 \mathrm{H})$-ylethanamine) which generated a neuroprotective effect by removing the $A \beta_{1-42}$ toxicity in hippocampal neurons and significantly improved spatial memory of AD affected mice [168].

\section{Conclusion and Future Perspective}

Why do researchers fail to identify drugs against AD? Although hundreds of molecules are present in the human brain, we believe $A \beta$ and Tau aggregation are the main hallmarks of $A D$ [169]. The hundreds of clinical trials targeting $A \beta$ and Tau proteins have failed due to other molecules excluding $A \beta$ and Tau proteins, which are invoking in initiating AD pathology. On the other hand, $A \beta$ or Tau proteins interact with several biomolecules such as the membranes, transition metal ions, cholesterol, apoE3, apoE4, prion, $\mathrm{Na}+, \mathrm{K}+$, omega3, omega6, and other molecules. The experimental studies could not render those interactions. In addition, experiments have faced two main hurdles with predicting antiAD drugs: unable to mimic the brain membrane exactly, prepared oligomers and fibrils structures are not resembling those presented in AD patients' brains. They cannot provide the high-resolution structure of the $A \beta$ oligomers. The atomic structural details of $A \beta$ aggregates are in great need. Computer simulation studies are not only prepared based on the supplementary details of NMR experiments, but they also provide more insight on $\mathrm{A} \beta$-Membrane and $\mathrm{A} \beta$-drug interactions when experiments studies are challenging. In this account, it is highly encouraged to pursue new investigations using computer simulations.

1. Omega3 and Omega6 polyunsaturated fatty acids are buried in the neuronal membranes and are linked to a slowing down and increasing the risk of $\mathrm{AD}$, respectively. Thus, it is essential to explore the dynamic mechanism of $A \beta_{1-40} / A \beta_{1-42}$ oligomers with and without interaction of metal ions in omega 3 and omega6 phospholipids as these details are lacking in the AD research.

2. Tyr10 residue in $A \beta_{1-42}$ regulates the toxic $\beta$-sheet formation and leads to aggregation, but none of the studies in the literature regarding the role of Tyr10 in metal-bound $A \beta_{1-42}$ peptide addressed this issue. In this perspective, investigating the interaction mechanism between metal-bound $A \beta_{1-42}$ peptides and lipid membranes will be a crucial step to describe the toxicity of $A \beta_{1-42}$ peptides.

3. The inhibitory effect of the number of natural compounds in the aggregation pathways has been explained in the manuscript. However, their actions remain to be elucidated. The transition metal ions, $\mathrm{Cu}^{2+}$ and $\mathrm{Zn}^{2+}$, and their bindings induced a higher tendency of $\beta$-sheet formation in the Leu17-Met35 regions of $A \beta_{1-42}$ peptide 
that can decrease solvent exposure (increase hydrophobicity) of the peptide which can lead to regulate toxicity [98]. To attenuate the hydrophobicity propensity of the peptide by the interaction of natural compounds, it is an essential investigation for anti-AD drug discovery.

4. Large evidence $[170,171]$ implicated the $A \beta_{1-42}$ peptide aggregation controlled by lipid membranes, but in contrast, cholesterol in the lipid membrane significantly enhances the peptide aggregation by cholesterol, showing a high affinity for the peptide. However, the detailed interaction and its connection between the lipid bilayer and membrane remains elusive. The new idea is to study how free and metal ions bound to $A \beta_{1-42}$ during aggregation changes in cholesterol-contained membranes.

5. The $A \beta_{25-35}$ cytotoxicity is well explained by the lipid bilayer mediated truncated $A \beta_{25-35}$ peptide aggregation, which has made perforation in the membrane causing uncontrollable permeation of $\mathrm{Ca}^{2+}$ ions [82]. So far, exploring the full-length of $\mathrm{A} \beta_{1-42}$ peptide aggregation in the presence or absence of $\mathrm{Cu}^{2+}, \mathrm{Zn}^{2+}$ and $\mathrm{Fe}^{2+}$ metal ions in the membrane remains an open research problem. Here one can describe the cytotoxicity of the full-length $A \beta_{1-42}$.

6. Advanced MD simulation, aided by the improved version of coarse-grained force fields (e.g., MARTINI 3, UNRES, PRIMO, etc), can describe large-scale systems and overcome time-scale limitations, and improve our understanding of the connection between $\mathrm{AD}$ progression and initial stages of the disease by tracing the molecular pathways of full-length $A \beta$ aggregation in complex with lipid bilayers. Similarly, it will help to unveil the fundamental role played by mechanical stability during amyloidogenesis and $A \beta$ aggregate maturation.

7. Our previous investigations have envisaged two molecules, M30 and gabapentin, blocking multiple steps of the A $\beta$ cascade: Aggregation, Synaptotoxicity, membrane pore formation, calcium dyshomeostasis and memory impairment. Thus, we strongly recommend using M30 and gabapentin as part of the clinical trial as an alternative $\mathrm{AD}$ treatment.

Author Contributions: S.B. and A.B.P. contributed equally in writing the manuscript. R.G.-J. reviewed, edited and made grammar corrections. All authors have read and agreed to the published version of the manuscript.

Funding: This research received fund from Dirección General de Asuntos del Personal Académico de la Universidad Nacional Autónoma de México (DGAPA-UNAM). This research financial supported by the National Science Centre, Poland, under Grant 2017/26/D/NZ1/00466, and from the Foundation for Polish Science under the grant MAB PLUS/11/2019.

Data Availability Statement: Not applicable.

Acknowledgments: S.B. acknowledged Dirección General de Asuntos del Personal Académico de la Universidad Nacional Autónoma de México (DGAPA-UNAM) for a postdoctoral Fellowship. A.B.P. acknowledges the National Science Centre, Poland, and the Foundation for Polish Science. Research was supported by PL-Grid Infrastructure and the TUL Computing \& Information Services Center infrastructure.

Conflicts of Interest: The authors declare no conflict of interest.
Abbreviations
A $\beta \quad$ Amyloid beta
AD Alzheimer's disease
MD Molecular dynamics
DFT Density Functional Theory
IDP Intrinsically disordered proteins
DMPC Dimyristoylgylcerophosphocholine
DPPC Dipalmitoylphosphatidylcholine 
DOPS Dioleoyl phosphatidylserine

POPC 1-palmitoyl-2-oleoyl-sn-glycero-3-phosphocholine

POPE Palmytoil-oleoyl-phosphatidylethanolamine

\section{References}

1. Alzheimer's Association. 2021 Alzheimer's Disease Facts and Figures. Alzheimer's Dement. 2021, 17, 327-406. [CrossRef]

2. Hardy, J.A.; Higgins, G.A. Alzheimer's Disease: The Amyloid Alzheimer's Disease. Science 1992, 256, 184-185. [CrossRef]

3. Bai, X.C.; Yan, C.; Yang, G.; Lu, P.; Ma, D.; Sun, L.; Zhou, R.; Scheres, S.H.W.; Shi, Y. An Atomic Structure of Human $\gamma$-Secretase. Nature 2015, 525, 212-217. [CrossRef] [PubMed]

4. Colvin, M.T.; Silvers, R.; Ni, Q.Z.; Can, T.V.; Sergeyev, I.; Rosay, M.; Donovan, K.J.; Michael, B.; Wall, J.; Linse, S.; et al. Atomic Resolution Structure of Monomorphic A 342 Amyloid Fibrils. J. Am. Chem. Soc. 2016, 138, 9663-9674. [CrossRef] [PubMed]

5. Wälti, M.A.; Ravotti, F.; Arai, H.; Glabe, C.G.; Wall, J.S.; Böckmann, A.; Güntert, P.; Meier, B.H.; Riek, R. Atomic-Resolution Structure of a Disease-Relevant A $\beta(1-42)$ Amyloid Fibril. Proc. Natl. Acad. Sci. USA 2016, 113, E4976-E4984. [CrossRef]

6. Gremer, L.; Schenk, C.; Reinartz, E.; Ravelli, R.B.G.; Tusche, M.; Lopez-iglesias, C.; Hoyer, W.; Heise, H.; Willbold, D. Fibril Structure of Amyloid-b (1-42) by Cryo-Electron Microscopy. Science 2017, 119, 116-119. [CrossRef]

7. Roberts, B.R.; Lind, M.; Wagen, A.Z.; Rembach, A.; Frugier, T.; Li, Q.X.; Ryan, T.M.; McLean, C.A.; Doecke, J.D.; Rowe, C.C.; et al. Biochemically-Defined Pools of Amyloid- $\beta$ in Sporadic Alzheimer's Disease: Correlation with Amyloid PET. Brain 2017, 140, 1486-1498. [CrossRef] [PubMed]

8. Kayed, R.; Head, E.; Thompson, J.L.; McIntire, T.M.; Milton, S.C.; Cotman, C.W.; Glabel, C.G. Common Structure of Soluble Amyloid Oligomers Implies Common Mechanism of Pathogenesis. Science 2003, 300, 486-489. [CrossRef] [PubMed]

9. O'Nuallain, B.; Wetzel, R. Conformational Abs Recognizing a Generic Amyloid Fibril Epitope. Proc. Natl. Acad. Sci. USA 2002, 99, 1485-1490. [CrossRef]

10. Michaels, T.C.T.; Šarić, A.; Curk, S.; Bernfur, K.; Arosio, P.; Meisl, G.; Dear, A.J.; Cohen, S.I.A.; Dobson, C.M.; Vendruscolo, M.; et al. Dynamics of Oligomer Populations Formed during the Aggregation of Alzheimer's A $\beta 42$ Peptide. Nat. Chem. 2020, 12, 445-451. [CrossRef]

11. Sevigny, J.; Chiao, P.; Bussière, T.; Weinreb, P.H.; Williams, L.; Maier, M.; Dunstan, R.; Salloway, S.; Chen, T.; Ling, Y.; et al. The Antibody Aducanumab Reduces A $\beta$ Plaques in Alzheimer's Disease. Nature 2016, 537, 50-56. [CrossRef] [PubMed]

12. Hanseeuw, B.J.; Betensky, R.A.; Jacobs, H.I.L.; Schultz, A.P.; Sepulcre, J.; Becker, J.A.; Cosio, D.M.O.; Farrell, M.; Quiroz, Y.T.; Mormino, E.C.; et al. Association of Amyloid and Tau with Cognition in Preclinical Alzheimer Disease: A Longitudinal Study. JAMA Neurol. 2019, 76, 915-924. [CrossRef] [PubMed]

13. Nguyen, P.H.; Ramamoorthy, A.; Sahoo, B.R.; Zheng, J.; Faller, P.; Straub, J.E.; Dominguez, L.; Shea, J.E.; Dokholyan, N.V.; de Simone, A.; et al. Amyloid Oligomers: A Joint Experimental/Computational Perspective on Alzheimer's Disease, Parkinson's Disease, Type II Diabetes, and Amyotrophic Lateral Sclerosis. Chem. Rev. 2021, 121, 2545-2647. [CrossRef]

14. Saravanan, K.M.; Zhang, H.; Zhang, H.; Xi, W.; Wei, Y. On the Conformational Dynamics of $\beta$-Amyloid Forming Peptides: A Computational Perspective. Front. Bioeng. Biotechnol. 2020, 8, 1-19. [CrossRef]

15. Robustelli, P.; Piana, S.; Shaw, D.E. Developing a Molecular Dynamics Force Field for Both Folded and Disordered Protein States. Proc. Natl. Acad. Sci. USA 2018, 115, E4758-E4766. [CrossRef]

16. Krupa, P.; Pham, D.Q.H.; Li, M.S. Properties of Monomeric A $\beta 42$ Probed by Different Sampling Methods and Force Fields: Role of Energy Components. J. Chem. Phys. 2019, 151, 055101. [CrossRef]

17. Kirkitadze, M.D.; Condron, M.M.; Teplow, D.B. Identification and Characterization of Key Kinetic Intermediates in Amyloid $\beta$-Protein Fibrillogenesis. J. Mol. Biol. 2001, 312, 1103-1119. [CrossRef] [PubMed]

18. Chong, S.H.; Chatterjee, P.; Ham, S. Computer Simulations of Intrinsically Disordered Proteins. Annu. Rev. Phys. Chem. 2017, 68, 117-134. [CrossRef]

19. Viet, M.H.; Nguyen, P.H.; Derreumaux, P.; Li, M.S. Effect of the English Familial Disease Mutation (H6R) on the Monomers and Dimers of $A \beta 40$ and $A \beta 42$. ACS Chem. Neurosci. 2014, 5, 646-657. [CrossRef]

20. Huy, P.D.Q.; Vuong, Q.V.; La Penna, G.; Faller, P.; Li, M.S. Impact of Cu(II) Binding on Structures and Dynamics of A $\beta 42$ Monomer and Dimer: Molecular Dynamics Study. ACS Chem. Neurosci. 2016, 7, 1348-1363. [CrossRef]

21. Nguyen, H.L.; Krupa, P.; Hai, N.M.; Linh, H.Q.; Li, M.S. Structure and Physicochemical Properties of the A $\beta 42$ Tetramer: Multiscale Molecular Dynamics Simulations. J. Phys. Chem. B 2019, 123, 7253-7269. [CrossRef]

22. Chong, S.H.; Ham, S. Assessing the Influence of Solvation Models on Structural Characteristics of Intrinsically Disordered Protein. Comput. Theor. Chem. 2013, 1017, 194-199. [CrossRef]

23. Best, R.B.; Zheng, W.; Mittal, J. Balanced Protein-Water Interactions Improve Properties of Disordered Proteins and Non-Specific Protein Association. J. Chem. Theory Comput. 2014, 10, 5113-5124. [CrossRef]

24. Piana, S.; Donchev, A.G.; Robustelli, P.; Shaw, D.E. Water Dispersion Interactions Strongly Influence Simulated Structural Properties of Disordered Protein States. J. Phys. Chem. B 2015, 119, 5113-5123. [CrossRef] [PubMed]

25. Rahman, M.U.; Rehman, A.U.; Liu, H.; Chen, H.F. Comparison and Evaluation of Force Fields for Intrinsically Disordered Proteins. J. Chem. Inf. Model. 2020, 60, 4912-4923. [CrossRef]

26. Ye, W.; Ji, D.; Wang, W.; Luo, R.; Chen, H.F. Test and Evaluation of Ff99IDPs Force Field for Intrinsically Disordered Proteins. J. Chem. Inf. Model. 2015, 55, 1021-1029. [CrossRef] [PubMed] 
27. Song, D.; Wang, W.; Ye, W.; Ji, D.; Luo, R.; Chen, H.F. Ff14IDPs Force Field Improving the Conformation Sampling of Intrinsically Disordered Proteins. Chem. Biol. Drug Des. 2017, 89, 5-15. [CrossRef] [PubMed]

28. Song, D.; Luo, R.; Chen, H.F. The IDP-Specific Force Field Ff14IDPSFF Improves the Conformer Sampling of Intrinsically Disordered Proteins. J. Chem. Inf. Model. 2017, 57, 1166-1178. [CrossRef]

29. Zhang, Y.; Liu, H.; Yang, S.; Luo, R.; Chen, H.F. Well-Balanced Force Field Ff03 CMAP for Folded and Disordered Proteins. J. Chem. Theory Comput. 2019, 15, 6769-6780. [CrossRef] [PubMed]

30. Maier, J.A.; Martinez, C.; Kasavajhala, K.; Wickstrom, L.; Hauser, K.E.; Simmerling, C. Ff14SB: Improving the Accuracy of Protein Side Chain and Backbone Parameters from Ff99SB. J. Chem. Theory Comput. 2015, 11, 3696-3713. [CrossRef]

31. Best, R.B.; Mittal, J. Protein Simulations with an Optimized Water Model: Cooperative Helix Formation and Temperature-Induced Unfolded State Collapse. J. Phys. Chem. B 2010, 114, 14916-14923. [CrossRef] [PubMed]

32. Huang, J.; Rauscher, S.; Nawrocki, G.; Ran, T.; Feig, M.; De Groot, B.L.; Grubmüller, H.; MacKerell, A.D. CHARMM36m: An Improved Force Field for Folded and Intrinsically Disordered Proteins. Nat. Methods 2016, 14, 71-73. [CrossRef] [PubMed]

33. Liu, H.; Song, D.; Zhang, Y.; Yang, S.; Luo, R.; Chen, H.F. Extensive Tests and Evaluation of the CHARMM36IDPSFF Force Field for Intrinsically Disordered Proteins and Folded Proteins. Phys. Chem. Chem. Phys. 2019, 21, 21918-21931. [CrossRef]

34. Piana, S.; Lindorff-Larsen, K.; Shaw, D.E. How Robust Are Protein Folding Simulations with Respect to Force Field Parameterization? Biophys. J. 2011, 100, L47-L49. [CrossRef]

35. Samantray, S.; Yin, F.; Kav, B.; Strodel, B. Different Force Fields Give Rise to Different Amyloid Aggregation Pathways in Molecular Dynamics Simulations. J. Chem. Inf. Model. 2020, 60, 6462-6475. [CrossRef]

36. Mu, J.; Liu, H.; Zhang, J.; Luo, R.; Chen, H.F. Recent Force Field Strategies for Intrinsically Disordered Proteins. J. Chem. Inf. Model. 2021, 61, 1037-1047. [CrossRef]

37. Kmiecik, S.; Gront, D.; Kolinski, M.; Wieteska, L.; Dawid, A.E.; Kolinski, A. Coarse-Grained Protein Models and Their Applications. Chem. Rev. 2016, 116, 7898-7936. [CrossRef]

38. Seo, M.; Rauscher, S.; Pomès, R.; Tieleman, D.P. Improving Internal Peptide Dynamics in the Coarse-Grained MARTINI Model: Toward Large-Scale Simulations of Amyloid- and Elastin-like Peptides. J. Chem. Theory Comput. 2012, 8, 1774-1785. [CrossRef] [PubMed]

39. Rojas, A.; Maisuradze, N.; Kachlishvili, K.; Scheraga, H.A.; Maisuradze, G.G. Elucidating Important Sites and the Mechanism for Amyloid Fibril Formation by Coarse-Grained Molecular Dynamics. ACS Chem. Neurosci. 2017, 8, 201-209. [CrossRef]

40. Latshaw, D.C.; Cheon, M.; Hall, C.K. Effects of Macromolecular Crowding on Amyloid Beta (16-22) Aggregation Using CoarseGrained Simulations. J. Phys. Chem. B 2014, 118, 13513-13526. [CrossRef] [PubMed]

41. Sahoo, A.; Xu, H.; Matysiak, S. Pathways of Amyloid-Beta Absorption and Aggregation in a Membranous Environment. Phys. Chem. Chem. Phys. 2019, 21, 8559-8568. [CrossRef]

42. Souza, P.C.T.; Alessandri, R.; Barnoud, J.; Thallmair, S.; Faustino, I.; Grünewald, F.; Patmanidis, I.; Abdizadeh, H.; Bruininks, B.M.H.; Wassenaar, T.A.; et al. Martini 3: A General Purpose Force Field for Coarse-Grained Molecular Dynamics. Nat. Methods 2021, 18, 382-388. [CrossRef]

43. Mahmood, M.I.; Poma, A.B.; Okazak, K.I. Optimizing Gō-MARTINI Coarse-Grained Model for F-BAR Protein on Lipid Membrane. Front. Mol. Biosci. 2021, 8, 1-10. [CrossRef]

44. Poma, A.B.; Cieplak, M.; Theodorakis, P.E. Combining the MARTINI and Structure-Based Coarse-Grained Approaches for the Molecular Dynamics Studies of Conformational Transitions in Proteins. J. Chem. Theory Comput. 2017, 13, 1366-1374. [CrossRef] [PubMed]

45. Poma, A.B.; Li, M.S.; Theodorakis, P.E. Generalization of the Elastic Network Model for the Study of Large Conformational Changes in Biomolecules. Phys. Chem. Chem. Phys. 2018, 20, 17020-17028. [CrossRef] [PubMed]

46. Ingólfsson, H.I.; Melo, M.N.; Van Eerden, F.J.; Arnarez, C.; Lopez, C.A.; Wassenaar, T.A.; Periole, X.; De Vries, A.H.; Tieleman, D.P.; Marrink, S.J. Lipid Organization of the Plasma Membrane. J. Am. Chem. Soc. 2014, 136, 14554-14559. [CrossRef]

47. Poma, A.B.; Guzman, H.V.; Li, M.S.; Theodorakis, P.E. Mechanical and Thermodynamic Properties of A $\beta 42$, A $\beta 40$, and $\alpha-$ Synuclein Fibrils: A Coarse-Grained Method to Complement Experimental Studies. Beilstein J. Nanotechnol. 2019, 10, 500-513. [CrossRef] [PubMed]

48. Chwastyk, M.; Bernaola, A.P.; Cieplak, M. Statistical Radii Associated with Amino Acids to Determine the Contact Map: Fixing the Structure of a Type i Cohesin Domain in the Clostridium Thermocellum Cellulosome. Phys. Biol. 2015, 12, 46002. [CrossRef]

49. Poma, A.B.; Chwastyk, M.; Cieplak, M. Elastic Moduli of Biological Fibers in a Coarse-Grained Model: Crystalline Cellulose and $\beta$-Amyloids. Phys. Chem. Chem. Phys. 2017, 19, 28195-28206. [CrossRef]

50. Poma, A.B.; Thu, T.T.M.; Tri, L.T.M.; Nguyen, H.L.; Li, M.S. Nanomechanical Stability of A $\beta$ Tetramers and Fibril-like Structures: Molecular Dynamics Simulations. J. Phys. Chem. B 2021, 125, 7628-7637. [CrossRef]

51. Sengupta, U.; Nilson, A.N.; Kayed, R. The Role of Amyloid-beta oligomers in Toxicity, Propogation, and Immunotherapy. EBioMedicine 2016, 6, 42-49. [CrossRef] [PubMed]

52. Hall, C.M.; Moeendarbary, E.; Sheridan, G.K. Mechanobiology of the Brain in Ageing and Alzheimer's Disease. Eur. J. Neurosci. 2021, 53, 3851-3878. [CrossRef] [PubMed]

53. Carballo-Pacheco, M.; Ismail, A.E.; Strodel, B. On the Applicability of Force Fields to Study the Aggregation of Amyloidogenic Peptides Using Molecular Dynamics Simulations. J. Chem. Theory Comput. 2018, 14, 6063-6075. [CrossRef] [PubMed] 
54. Senguen, F.T.; Doran, T.M.; Anderson, E.A.; Nilsson, B.L. Clarifying the Influence of Core Amino Acid Hydrophobicity, Secondary Structure Propensity, and Molecular Volume on Amyloid- $\beta$ 16-22 Self-Assembly. Mol. Biosyst. 2011, 7, 497-510. [CrossRef]

55. Lockhart, C.; Smith, A.K.; Klimov, D.K. Three Popular Force Fields Predict Consensus Mechanism of Amyloid $\beta$ Peptide Binding to the Dimyristoylgylcerophosphocholine Bilayer. J. Chem. Inf. Model. 2020, 60, 2282-2293. [CrossRef] [PubMed]

56. Akbayraka, I.Y.; Caglayanb, S.I.; Ozcanb, Z.; Uverskyc, V.N.; Coskuner-Weberb, O. Current Challenges and Limitations in the Studies of Intrinsically Disordered Proteins in Neurodegenerative Diseases by Computer Simulations. Curr. Alzheimer Res. 2020, 17, 805-818. [CrossRef]

57. Press-Sandler, O.; Miller, Y. Molecular Mechanisms of Membrane-Associated Amyloid Aggregation: Computational Perspective and Challenges. Biochim. Biophys. Acta-Biomembr. 2018, 1860, 1889-1905. [CrossRef] [PubMed]

58. Davis, C.H.; Berkowitz, M.L. Interaction between Amyloid- $\beta$ (1-42) Peptide and Phospholipid Bilayers: A Molecular Dynamics Study. Biophys. J. 2009, 96, 785-797. [CrossRef] [PubMed]

59. Davis, C.H.; Berkowitz, M.L. Structure of the Amyloid- $\beta$ (1-42) Monomer Absorbed to Model Phospholipid Bilayers: A Molecular Dynamics Study. J. Phys. Chem. B 2009, 113, 14480-14486. [CrossRef]

60. Lockhart, C.; Klimov, D.K. Calcium Enhances Binding of A $\beta$ Monomer to DMPC Lipid Bilayer. Biophys. J. 2015, 108, 1807-1818. [CrossRef]

61. Pike, C.J.; Burdick, D.; Walencewicz, A.J.; Glabe, C.G.; Cotman, C.W. Neurodegeneration Induced by $\beta$-Amyloid Peptides in Vitro: The Role of Peptide Assembly State. J. Neurosci. 1993, 13, 1676-1687. [CrossRef]

62. Millucci, L.; Ghezzi, L.; Bernardini, G.; Santucci, A. Conformations and Biological Activities of Amyloid Beta Peptide 25-35. Curr. Protein Pept. Sci. 2009, 999, 1-6. [CrossRef]

63. Smith, A.K.; Klimov, D.K. Binding of Cytotoxic Aß25-35 Peptide to the Dimyristoylphosphatidylcholine Lipid Bilayer. J. Chem. Inf. Model. 2018, 58, 1053-1065. [CrossRef]

64. Jang, H.; Connelly, L.; Teran Arce, F.; Ramachandran, S.; Kagan, B.L.; Lal, R.; Nussinov, R. Mechanisms for the Insertion of Toxic, Fibril-like $\beta$-Amyloid Oligomers into the Membrane. J. Chem. Theory Comput. 2013, 9, 822-833. [CrossRef]

65. Davis, C.H.; Berkowitz, M.L. A Molecular Dynamics Study of the Early Stages of Amyloid- $\beta$ (1-42) Oligomerization: The Role of Lipid Membranes. Proteins Struct. Funct. Bioinform. 2010, 78, 2533-2545. [CrossRef] [PubMed]

66. Snowden, S.G.; Ebshiana, A.A.; Hye, A.; An, Y.; Pletnikova, O.; O’Brien, R.; Troncoso, J.; Legido-Quigley, C.; Thambisetty, M. Association between Fatty Acid Metabolism in the Brain and Alzheimer Disease Neuropathology and Cognitive Performance: A Nontargeted Metabolomic Study. PLoS Med. 2017, 14, e1002266. [CrossRef] [PubMed]

67. Lu, Y.; Shi, X.F.; Nguyen, P.H.; Sterpone, F.; Salsbury, F.R.; Derreumaux, P. Amyloid- $\beta(29-42)$ Dimeric Conformations in Membranes Rich in Omega-3 and Omega-6 Polyunsaturated Fatty Acids. J. Phys. Chem. B 2019, 123, 2687-2696. [CrossRef]

68. Jana, M.K.; Cappai, R.; Pham, C.L.L.; Ciccotosto, G.D. Membrane-Bound Tetramer and Trimer A $\beta$ Oligomeric Species Correlate with Toxicity towards Cultured Neurons. J. Neurochem. 2016, 136, 594-608. [CrossRef]

69. Doig, A.J.; Castillo-frias, M.P.; Berthoumieu, O.; Tarus, B.; Nasica-labouze, J.; Sterpone, F.; Nguyen, P.H.; Hooper, N.M.; Faller, P.; Derreumaux, P. Why Is Research on Amyloid- $\beta$ Failing to Give New Drugs for Alzheimer's Disease? ACS Chem. Neurosci. 2017, 8, 1435-1437. [CrossRef] [PubMed]

70. Ngo, S.T.; Hung, H.M.; Tran, K.N.; Nguyen, M.T. Replica Exchange Molecular Dynamics Study of the Amyloid Beta (11-40) Trimer Penetrating a Membrane. RSC Adv. 2017, 7, 7346-7357. [CrossRef]

71. Ngo, S.T.; Nguyen, M.T.; Nguyen, N.T.; Vu, V.V. The Effects of A21G Mutation on Transmembrane Amyloid Beta (11-40) Trimer: An in Silico Study. J. Phys. Chem. B 2017, 121, 8467-8474. [CrossRef] [PubMed]

72. Tran, T.T.; Pan, F.; Tran, L.; Roland, C.; Sagui, C. The F19W Mutation Reduces the Binding Affinity of the Transmembrane A $\beta 11-40$ trimer to the Membrane Bilayer. RSC Adv. 2021, 11, 2664-2676. [CrossRef]

73. Poojari, C.; Strodel, B. Stability of Transmembrane Amyloid $\beta$-Peptide and Membrane Integrity Tested by Molecular Modeling of Site-Specific A $\beta 42$ Mutations. PLoS ONE 2013, 8, e78399. [CrossRef]

74. Murakami, K.; Irie, K.; Morimoto, A.; Ohigashi, H.; Shindo, M.; Nagao, M.; Shimizu, T.; Shirasawa, T. Neurotoxicity and Physicochemical Properties of A $\beta$ Mutant Peptides from Cerebral Amyloid Angiopathy: Implication for the Pathogenesis of Cerebral Amyloid Angiopathy and Alzheimer's Disease. J. Biol. Chem. 2003, 278, 46179-46187. [CrossRef]

75. Luheshi, L.M.; Tartaglia, G.G.; Brorsson, A.C.; Pawar, A.P.; Watson, I.E.; Chiti, F.; Vendruscolo, M.; Lomas, D.A.; Dobson, C.M.; Crowther, D.C. Systematic in Vivo Analysis of the Intrinsic Determinants of Amyloid $\beta$ Pathogenicity. PLoS Biol. 2007, 5, e290. [CrossRef]

76. Petkova, A.T.; Yau, W.M.; Tycko, R. Experimental Constraints on Quaternary Structure in Alzheimer's $\beta$-Amyloid Fibrils. Biochemistry 2006, 45, 498-512. [CrossRef]

77. Yung, S.K.; Liu, L.; Axelsen, P.H.; Hochstrasser, R.M. 2D IR Provides Evidence for Mobile Water Molecules in $\beta$-Amyloid Fibrils. Proc. Natl. Acad. Sci. USA 2009, 106, 17751-17756. [CrossRef]

78. Wang, T.; Jo, H.; DeGrado, W.F.; Hong, M. Water Distribution, Dynamics, and Interactions with Alzheimer's $\beta$-Amyloid Fibrils Investigated by Solid-State NMR. J. Am. Chem. Soc. 2017, 139, 6242-6252. [CrossRef] [PubMed]

79. Xi, W.; Hansmann, U.H.E. Ring-like N-Fold Models of A $\beta 42$ Fibrils. Sci. Rep. 2017, 7, 1-14. [CrossRef] [PubMed]

80. Serra-Batiste, M.; Ninot-Pedrosa, M.; Bayoumi, M.; Gairí, M.; Maglia, G.; Carulla, N. A $\beta 42$ Assembles into Specific $\beta$-Barrel Pore-Forming Oligomers in Membrane-Mimicking Environments. Proc. Natl. Acad. Sci. USA 2016, 113, 10866-10871. [CrossRef] 
81. Ciudad, S.; Puig, E.; Botzanowski, T.; Meigooni, M.; Arango, A.S.; Do, J.; Mayzel, M.; Bayoumi, M.; Chaignepain, S.; Maglia, G.; et al. A $\beta(1-42)$ Tetramer and Octamer Structures Reveal Edge Conductivity Pores as a Mechanism for Membrane Damage. Nat. Commun. 2020, 11, 1-14. [CrossRef] [PubMed]

82. Smith, A.K.; Klimov, D.K. De Novo Aggregation of Alzheimer's Aß25-35 Peptides in a Lipid Bilayer. Sci. Rep. 2019, 9, 1-12. [CrossRef] [PubMed]

83. Tofoleanu, F.; Brooks, B.R.; Buchete, N.V. Modulation of Alzheimers A $\beta$ Protofilament-Membrane Interactions by Lipid Headgroups. ACS Chem. Neurosci. 2015, 6, 446-455. [CrossRef]

84. Qiang, W.; Doherty, K.E.; Klees, L.M.; Tobin-Miyaji, Y. Time-Dependent Lipid Dynamics, Organization and Peptide-Lipid Interaction in Phospholipid Bilayers with Incorporated $\beta$-Amyloid Oligomers. J. Phys. Chem. Lett. 2020, 11, 8329-8336. [CrossRef] [PubMed]

85. Fernández-Pérez, E.J.; Sepúlveda, F.J.; Peters, C.; Bascuñán, D.; Riffo-Lepe, N.O.; González-Sanmiguel, J.; Sánchez, S.A.; Peoples, R.W.; Vicente, B.; Aguayo, L.G. Effect of Cholesterol on Membrane Fluidity and Association of A $\beta$ Oligomers and Subsequent Neuronal Damage: A Double-Edged Sword. Front. Aging Neurosci. 2018, 10, 1-14. [CrossRef] [PubMed]

86. D'Errico, G.; Vitiello, G.; Ortona, O.; Tedeschi, A.; Ramunno, A.; D'Ursi, A.M. Interaction between Alzheimer's A $\beta(25-35)$ Peptide and Phospholipid Bilayers: The Role of Cholesterol. Biochim. Biophys. Acta-Biomembr. 2008, 1778, 2710-2716. [CrossRef]

87. Di Scala, C.; Troadec, J.D.; Lelièvre, C.; Garmy, N.; Fantini, J.; Chahinian, H. Mechanism of Cholesterol-Assisted Oligomeric Channel Formation by a Short Alzheimer $\beta$-Amyloid Peptide. J. Neurochem. 2014, 128, 186-195. [CrossRef]

88. Di Scala, C.; Chahinian, H.; Yahi, N.; Garmy, N.; Fantini, J. Interaction of Alzheimer's $\beta$-Amyloid Peptides with Cholesterol: Mechanistic Insights into Amyloid Pore Formation. Biochemistry 2014, 53, 4489-4502. [CrossRef] [PubMed]

89. Di Scala, C.; Yahi, N.; Garmy, N.; Chahinian, H.; Fantini, J. Biochemical Identi Fi Cation of a Linear Cholesterol-Binding Domain within Alzheimer's $\beta$ Amyloid Peptide. ACS Chem. Neurosci. 2013, 4, 509-517. [CrossRef]

90. Avdulov, N.A.; Chochina, S.V.; Igbavboa, U.; Warden, C.S.; Vassiliev, A.V.; Wood, W.G. Lipid Binding to Amyloid $\beta$-Peptide Aggregates: Preferential Binding of Cholesterol as Compared with Phosphatidylcholine and Fatty Acids. J. Neurochem. 1997, 69, 1746-1752. [CrossRef]

91. Yu, X.; Zheng, J. Cholesterol Promotes the Interaction of Alzheimer $\beta$-Amyloid Monomer with Lipid Bilayer. J. Mol. Biol. 2012, 421, 561-571. [CrossRef] [PubMed]

92. Zhao, L.N.; Chiu, S.W.; Benoit, J.; Chew, L.Y.; Mu, Y. Amyloid $\beta$ Peptides Aggregation in a Mixed Membrane Bilayer: A Molecular Dynamics Study. J. Phys. Chem. B 2011, 115, 12247-12256. [CrossRef] [PubMed]

93. Abramov, A.Y.; Ionov, M.; Pavlov, E.; Duchen, M.R. Membrane Cholesterol Content Plays a Key Role in the Neurotoxicity of $\beta$-Amyloid: Implications for Alzheimer's Disease. Aging Cell 2011, 10, 595-603. [CrossRef] [PubMed]

94. Dias, C.L.; Jalali, S.; Yang, Y.; Cruz, L. Role of Cholesterol on Binding of Amyloid Fibrils to Lipid Bilayers. J. Phys. Chem. B 2020, 124, 3036-3042. [CrossRef]

95. Lovell, M.A.; Robertson, J.D.; Teesdale, W.J.; Campbell, J.L.; Markesbery, W.R. Copper, Iron and Zinc in Alzheimer's Disease Senile Plaques. J. Neurol. Sci. 1998, 158, 47-52. [CrossRef]

96. Candy, J.M.; Klinowski, J.; Perry, R.H.; Perry, E.K.; Fairbairn, A.; Oakley, A.E.; Carpenter, T.A.; Atack, J.R.; Blessed, G.; Edwardson, J.A. Aluminosilicates and Senile Plaque Formation in Alzheimer'S Disease. Lancet 1986, 327, 354-356. [CrossRef]

97. Boopathi, S.; Kolandaivel, P. Role of Zinc and Copper Metal Ions in Amyloid $\beta$-Peptides A $\beta_{1-40}$ and A $\beta_{1-42}$ Aggregation. RSC Adv. 2014, 4, 38951-38965. [CrossRef]

98. Boopathi, S.; Huy, P.D.Q.; González, W.; Theodorakis, P.E.; Li, M.S. Zinc Binding Promotes Greater Hydrophobicity in Alzheimer's A $\beta 1-42$ Peptide than Copper Binding: Molecular Dynamics and Solvation Thermodynamics Studies. Proteins 2020, 88, 1285-1302. [CrossRef]

99. Miller, Y.; Ma, B.; Nussinov, R. Zinc Ions Promote Alzheimer A Aggregation via Population Shift of Polymorphic States. Proc. Natl. Acad. Sci. USA 2010, 107, 9490-9495. [CrossRef]

100. Lee, M.; Kim, J.I.; Na, S.; Eom, K. Metal Ions Affect the Formation and Stability of Amyloid $\beta$ Aggregates at Multiple Length Scales. Phys. Chem. Chem. Phys. 2018, 20, 8951-8961. [CrossRef]

101. Hensley, K.; Maidt, M.L.; Yu, Z.; Sang, H.; Markesbery, W.R.; Floyd, R.A. Electrochemical Analysis of Protein Nitrotyrosine and Dityrosine in the Alzheimer Brain Indicates Region-Specific Accumulation. J. Neurosci. 1998, 18, 8126-8132. [CrossRef] [PubMed]

102. Gu, M.; Bode, D.C.; Viles, J.H. Copper Redox Cycling Inhibits A $\beta$ Fibre Formation and Promotes Fibre Fragmentation, While Generating a Dityrosine A $\beta$ Dimer. Sci. Rep. 2018, 8, 1-14. [CrossRef] [PubMed]

103. De Santis, E.; Minicozzi, V.; Proux, O.; Rossi, G.; Silva, K.I.; Lawless, M.J.; Stellato, F.; Saxena, S.; Morante, S. Cu(II)-Zn(II) Cross-Modulation in Amyloid-Beta Peptide Binding: An X-ray Absorption Spectroscopy Study. J. Phys. Chem B 2015, 119, 15813-15820. [CrossRef] [PubMed]

104. Srivastava, A.K.; Pittman, J.M.; Zerweck, J.; Venkata, B.S.; Moore, P.C.; Sachleben, J.R.; Meredith, S.C. $\beta$-Amyloid Aggregation and Heterogeneous Nucleation. Protein Sci. 2019, 28, 1567-1581. [CrossRef]

105. Vázquez De La Torre, A.; Gay, M.; Vilaprinyó-Pascual, S.; Mazzucato, R.; Serra-Batiste, M.; Vilaseca, M.; Carulla, N. Direct Evidence of the Presence of Cross-Linked A $\beta$ Dimers in the Brains of Alzheimer's Disease Patients. Anal. Chem. 2018, 90, 4552-4560. [CrossRef]

106. Coskuner, O.; Uversky, V.N. Tyrosine Regulates $\beta$-Sheet Structure Formation in Amyloid-B42: A New Clustering Algorithm for Disordered Proteins. J. Chem. Inf. Model. 2017, 57, 1342-1358. [CrossRef] 
107. Orr, M.E.; Garbarino, V.R.; Salinas, A.; Buffenstein, R. Sustained High Levels of Neuroprotective, High Molecular Weight, Phosphorylated Tau in the Longest-Lived Rodent. Neurobiol. Aging 2015, 36, 1496-1504. [CrossRef]

108. Bush, A.I.; Pettingell, W.H.; Multhaup, G.; Paradis, M.D.; Vonsattel, J.P.; Gusella, J.F.; Beyreuther, K.; Masters, C.L.; Tanzi, R.E. Rapid Induction of Alzheimer A $\beta$ Amyloid Formation by Zinc. Science 1994, 265, 1464-1467. [CrossRef]

109. Kozin, S.A.; Mezentsev, Y.V.; Kulikova, A.A.; Indeykina, M.I.; Golovin, A.V.; Ivanov, A.S.; Tsvetkov, P.O.; Makarov, A.A. ZincInduced Dimerization of the Amyloid- $\beta$ Metal-Binding Domain 1-16 Is Mediated by Residues 11-14. Mol. Biosyst. 2011, 7, 1053-1055. [CrossRef]

110. Cherny, R.A.; Atwood, C.S.; Xilinas, M.E.; Gray, D.N.; Jones, W.D.; McLean, C.A.; Barnham, K.J.; Volitakis, I.; Fraser, F.W.; Kim, Y.S.; et al. Treatment with a Copper-Zinc Chelator Markedly and Rapidly Inhibits $\beta$-Amyloid Accumulation in Alzheimer's Disease Transgenic Mice. Neuron 2001, 30, 665-676. [CrossRef]

111. Guilloreau, L.; Combalbert, S.; Sournia-Saquet, M.; Mazarguil, H.; Faller, P. Redox Chemistry of Copper-Amyloid- $\beta$ : The Generation of Hydroxyl Radical in the Presence of Ascorbate Is Linked to Redox-Potentials and Aggregation State. ChemBioChem 2007, 8, 1317-1325. [CrossRef] [PubMed]

112. Boopathi, S.; Kolandaivel, P. Fe2 ${ }^{+}$Binding on Amyloid $\beta$-Peptide Promotes Aggregation. Proteins Struct. Funct. Bioinform. 2016, 84, 1257-1274. [CrossRef]

113. Tycko, R. Molecular Structure of Amyloid Fibrils: Insights from Solid-State NMR. Q. Rev. Biophys. 2006, 39, 1-55. [CrossRef] [PubMed]

114. Turner, M.; Mutter, S.T.; Kennedy-Britten, O.D.; Platts, J.A. Molecular Dynamics Simulation of Aluminium Binding to Amyloid- $\beta$ and Its Effect on Peptide Structure. PLoS ONE 2019, 14, e0217992. [CrossRef] [PubMed]

115. Platts, J.A. Quantum Chemical Molecular Dynamics and Metadynamics Simulation of Aluminium Binding to Amyloid- $\beta$ and Related Peptides. R. Soc. Open Sci. 2020, 7, 191562. [CrossRef]

116. Roldán-Martín, L.; Peccati, F.; Sciortino, G.; Sodupe, M.; Maréchal, J.-D. Impact of Cu(II) and Al(III) on the Conformational Landscape of Amyloidb1-42. Phys. Chem. Chem. Phys. 2021, 23, 13023-13032. [CrossRef]

117. Wallin, C.; Jarvet, J.; Biverstål, H.; Wärmländer, S.; Danielsson, J.; Gräslund, A.; Abelein, A. Metal Ion Coordination Delays Amyloid- $\beta$ Peptide Self-Assembly by Forming an Aggregation-Inert Complex. J. Biol. Chem. 2020, 295, 7224-7234. [CrossRef]

118. Basha, M.R.; Wei, W.; Bakheet, S.A.; Benitez, N.; Siddiqi, H.K.; Ge, Y.W.; Lahiri, D.K.; Zawia, N.H. The Fetal Basis of Amyloidogenesis: Exposure to Lead and Latent Overexpression of Amyloid Precursor Protein and $\beta$-Amyloid in the Aging Brain. J. Neurosci. 2005, 25, 823-829. [CrossRef]

119. Wu, J.; Basha, M.R.; Brock, B.; Cox, D.P.; Cardozo-Pelaez, F.; McPherson, C.A.; Harry, J.; Rice, D.C.; Maloney, B.; Chen, D.; et al. Alzheimer's Disease (AD)-like Pathology in Aged Monkeys after Infantile Exposure to Environmental Metal Lead (Pb): Evidence for a Developmental Origin and Environmental Link for AD. J. Neurosci. 2008, 28, 3-9. [CrossRef]

120. Wallin, C.; Sholts, S.B.; Österlund, N.; Luo, J.; Jarvet, J.; Roos, P.M.; Ilag, L.; Gräslund, A.; Wärmländer, S.K.T.S. Alzheimer's Disease and Cigarette Smoke Components: Effects of Nicotine, PAHs, and Cd(II), Cr(III), Pb(II), Pb(IV) Ions on Amyloid- $\beta$ Peptide Aggregation. Sci. Rep. 2017, 7, 1-14. [CrossRef]

121. Charlet, L.; Chapron, Y.; Faller, P.; Kirsch, R.; Stone, A.T.; Baveye, P.C. Neurodegenerative Diseases and Exposure to the Environmental Metals Mn, Pb, and Hg. Coord. Chem. Rev. 2012, 256, 2147-2163. [CrossRef]

122. Meleleo, D.; Notarachille, G.; Mangini, V.; Arnesano, F. Concentration-Dependent Effects of Mercury and Lead on A $\beta 42:$ Possible Implications for Alzheimer's Disease. Eur. Biophys. J. 2019, 48, 173-187. [CrossRef] [PubMed]

123. Wallin, C.; Friedemann, M.; Sholts, S.B.; Noormägi, A.; Svantesson, T.; Jarvet, J.; Roos, P.M.; Palumaa, P.; Gräslund, A.; Wärmländer, S.K.T.S. Mercury and Alzheimer's Disease: $\mathrm{Hg}$ (II) Ions Display Specific Binding to the Amyloid- $\beta$ Peptide and Hinder Its Fibrillization. Biomolecules 2020, 10, 44. [CrossRef] [PubMed]

124. Banta, R.G.; Markesbery, W.R. Elevated Manganese Levels Associated with Dementia and Extrapyramidal Signs. Neurology 1977, 27, 213-216. [CrossRef] [PubMed]

125. Wallin, C.; Kulkarni, Y.S.; Abelein, A.; Jarvet, J.; Liao, Q.; Strodel, B.; Olsson, L.; Luo, J.; Abrahams, J.P.; Sholts, S.B.; et al. Characterization of Mn(II) Ion Binding to the Amyloid- $\beta$ Peptide in Alzheimer's Disease. J. Trace Elem. Med. Biol. 2016, 38, 183-193. [CrossRef] [PubMed]

126. Zirah, S.; Kozin, S.A.; Mazur, A.K.; Blond, A.; Cheminant, M.; Ségalas-Milazzo, I.; Debey, P.; Rebuffat, S. Structural Changes of Region 1-16 of the Alzheimer Disease Amyloid $\beta$-Peptide upon Zinc Binding and in Vitro Aging. J. Biol. Chem. 2006, 281, 2151-2161. [CrossRef] [PubMed]

127. Lin, G.; Li, X.; Cheng, X.; Zhao, N.; Zheng, W. Manganese Exposure Aggravates $\beta$-Amyloid Pathology by Microglial Activation. Front. Aging Neurosci. 2020, 12, 1-15. [CrossRef]

128. Hampel, H.; Lista, S.; Mango, D.; Nisticò, R.; Perry, G.; Avila, J.; Hernandez, F.; Geerts, H.; Vergallo, A. Lithium as a Treatment for Alzheimer's Disease: The Systems Pharmacology Perspective. J. Alzheimer's Dis. 2019, 69, 615-629. [CrossRef]

129. Velosa, J.; Delgado, A.; Finger, E.; Berk, M.; Kapczinski, F.; de Azevedo Cardoso, T. Risk of Dementia in Bipolar Disorder and the Interplay of Lithium: A Systematic Review and Meta-Analyses. Acta Psychiatr. Scand. 2020, 141, 510-521. [CrossRef] [PubMed]

130. Pan, Y.; Short, J.L.; Newman, S.A.; Choy, K.H.C.; Tiwari, D.; Yap, C.; Senyschyn, D.; Banks, W.A.; Nicolazzo, J.A. Cognitive Benefits of Lithium Chloride in APP/PS1 Mice Are Associated with Enhanced Brain Clearance of $\beta$-Amyloid. Brain Behav. Immun. 2018, 70, 36-47. [CrossRef] [PubMed] 
131. Habib, A.; Shytle, R.D.; Sawmiller, D.; Koilraj, S.; Munna, S.A.; Rongo, D.; Hou, H.; Borlongan, C.V.; Currier, G.; Tan, J. Comparing the Effect of the Novel Ionic Cocrystal of Lithium Salicylate Proline (LISPRO) with Lithium Carbonate and Lithium Salicylate on Memory and Behavior in Female APPswe/PS1dE9 Alzheimer's Mice. J. Neurosci. Res. 2019, 97, 1066-1080. [CrossRef]

132. Xiang, J.; Cao, K.; Dong, Y.T.; Xu, Y.; Li, Y.; Song, H.; Zeng, X.X.; Ran, L.Y.; Hong, W.; Guan, Z.Z. Lithium Chloride Reduced the Level of Oxidative Stress in Brains and Serums of APP/PS1 Double Transgenic Mice via the Regulation of GSK3 $\beta / N r f 2 / H O-1$ Pathway. Int. J. Neurosci. 2020, 130, 564-573. [CrossRef]

133. Liu, M.; Qian, T.; Zhou, W.; Tao, X.; Sang, S.; Zhao, L. Beneficial Effects of Low-Dose Lithium on Cognitive Ability and Pathological Alteration of Alzheimer's Disease Transgenic Mice Model. Neuroreport 2020, 31, 943-951. [CrossRef] [PubMed]

134. Berntsson, E.; Paul, S.; Vosough, F.; Sholts, S.B.; Jarvet, J.; Roos, P.M.; Barth, A.; Gräslund, A.; Wärmländer, S.K.T.S. Lithium Ions Display Weak Interaction with Amyloid-Beta $(\mathrm{A} \beta)$ Peptides and Have Minor Effects on Their Aggregation. Acta Biochim. Pol. 2021, 68, 169-179. [CrossRef] [PubMed]

135. Eketjäll, S.; Janson, J.; Kaspersson, K.; Bogstedt, A.; Jeppsson, F.; Fälting, J.; Haeberlein, S.B.; Kugler, A.R.; Alexander, R.C.; Cebers, G. AZD3293: A Novel, Orally Active BACE1 Inhibitor with High Potency and Permeability and Markedly Slow Off-Rate Kinetics. J. Alzheimer's Dis. 2016, 50, 1109-1123. [CrossRef] [PubMed]

136. Athar, T.; Al Balushi, K.; Khan, S.A. Recent Advances on Drug Development and Emerging Therapeutic Agents for Alzheimer's Disease. Mol. Biol. Rep. 2021, 48, 5629-5645. [CrossRef] [PubMed]

137. Hassan, M.; Abbas, Q.; Seo, S.Y.; Shahzadi, S.; Al Ashwal, H.; Zaki, N.; Iqbal, Z.; Moustafa, A.A. Computational Modeling and Biomarker Studies of Pharmacological Treatment of Alzheimer's Disease (Review). Mol. Med. Rep. 2018, 18, 639-655. [CrossRef] [PubMed]

138. Imbimbo, B.P. Alzheimer's Disease: $\gamma$-Secretase Inhibitors. Drug Discov. Today Ther. Strateg. 2008, 5, 169-175. [CrossRef]

139. Hopkins, C.R. ACS Chemical Neuroscience Molecule Spotlight on BMS-708163. ACS Chem. Neurosci. 2012, 3, 149-150. [CrossRef]

140. Hopkins, C.R. ACS Chemical Neuroscience Molecule Spotlight on Semagacestat (Ly450139). ACS Chem. Neurosci. 2010, 1, 533-534. [CrossRef]

141. Hopkins, C.R. ACS Chemical Neuroscience Molecule Spotlight on Begacestat (GSI- 953). ACS Chem. Neurosci. 2012, 3, 3-4. [CrossRef] [PubMed]

142. Siemers, E.R.; Sundell, K.L.; Carlson, C.; Case, M.; Sethuraman, G.; Liu-seifert, H.; Dowsett, S.A.; Pontecorvo, M.J.; Dean, R.A.; Demattos, R. Phase 3 Solanezumab Trials: Secondary Outcomes in Mild Alzheimer's Disease Patients. Alzheimer's Dement. 2016, 12, 110-120. [CrossRef]

143. Ostrowitzki, S.; Lasser, R.A.; Dorflinger, E.; Scheltens, P.; Barkhof, F.; Nikolcheva, T.; Ashford, E.; Retout, S.; Hofmann, C.; Delmar, P.; et al. A Phase III Randomized Trial of Gantenerumab in Prodromal Alzheimer's Disease. Alzheimer's Res. Ther. 2017, 9, 1-15. [CrossRef]

144. Tucker, S.; Möller, C.; Tegerstedt, K.; Lord, A.; Laudon, H.; Sjödahl, J.; Söderberg, L.; Spens, E.; Sahlin, C.; Waara, E.R.; et al. The Murine Version of BAN2401 (MAb158) Selectively Reduces Amyloid- $\beta$ Protofibrils in Brain and Cerebrospinal Fluid of Tg-ArcSwe Mice. J. Alzheimer's Dis. 2015, 43, 575-588. [CrossRef] [PubMed]

145. Mueller-Steiner, S.; Zhou, Y.; Arai, H.; Roberson, E.D.; Sun, B.; Chen, J.; Wang, X.; Yu, G.; Esposito, L.; Mucke, L.; et al. Antiamyloidogenic and Neuroprotective Functions of Cathepsin B: Implications for Alzheimer's Disease. Neuron 2006, 51, 703-714. [CrossRef] [PubMed]

146. DeMattos, R.B.; Bales, K.R.; Cummins, D.J.; Dodart, J.C.; Paul, S.M.; Holtzman, D.M. Peripheral Anti-A $\beta$ Antibody Alters CNS and Plasma A $\beta$ Clearance and Decreases Brain A $\beta$ Burden in a Mouse Model of Alzheimer's Disease. Proc. Natl. Acad. Sci. USA 2001, 98, 8850-8855. [CrossRef] [PubMed]

147. Lannfelt, L.; Relkin, N.R.; Siemers, E.R. Amyloid-B-Directed Immunotherapy for Alzheimer's Disease. J. Intern. Med. 2014, 275, 284-295. [CrossRef] [PubMed]

148. Crespi, G.A.N.; Hermans, S.J.; Parker, M.W.; Miles, L.A. Molecular Basis for Mid-Region Amyloid- $\beta$ Capture by Leading Alzheimer's Disease Immunotherapies. Sci. Rep. 2015, 5, 2-6. [CrossRef]

149. Schneider, L. A Resurrection of Aducanumab for Alzheimer's Disease. Lancet Neurol. 2020, 19, 111-112. [CrossRef]

150. Cummings, J.; Aisen, P.; Lemere, C.; Atri, A.; Sabbagh, M.; Salloway, S. Aducanumab Produced a Clinically Meaningful Benefit in Association with Amyloid Lowering. Alzheimer's Res. Ther. 2021, 13, 10-12. [CrossRef]

151. FDA Grants Accelerated Approval for Alzheimer's Drug. Available online: https://doi.org/https://www.fda.gov/news-events / press-announcements / fda-grants-accelerated-approval-alzheimers-drug (accessed on 7 June 2021).

152. Arndt, J.W.; Qian, F.; Smith, B.A.; Quan, C.; Kilambi, K.P.; Bush, M.W.; Walz, T.; Pepinsky, R.B.; Bussière, T.; Hamann, S.; et al. Structural and Kinetic Basis for the Selectivity of Aducanumab for Aggregated Forms of Amyloid- $\beta$. Sci. Rep. 2018, 8, 1-16. [CrossRef] [PubMed]

153. Frost, C.V.; Zacharias, M. From Monomer to Fibril: Abeta-Amyloid Binding to Aducanumab Antibody Studied by Molecular Dynamics Simulation. Proteins Struct. Funct. Bioinform. 2020, 88, 1592-1606. [CrossRef] [PubMed]

154. Peters, C.; Fernandez-Perez, E.J.; Burgos, C.F.; Espinoza, M.P.; Castillo, C.; Urrutia, J.C.; Streltsov, V.A.; Opazo, C.; Aguayo, L.G. Inhibition of Amyloid Beta-Induced Synaptotoxicity by a Pentapeptide Derived from the Glycine Zipper Region of the Neurotoxic Peptide. Neurobiol. Aging 2013, 34, 2805-2814. [CrossRef] [PubMed] 
155. Zheng, X.; Wu, C.; Liu, D.; Li, H.; Bitan, G.; Shea, J.E.; Bowers, M.T. Mechanism of C-Terminal Fragments of Amyloid $\beta$-Protein as A $\beta$ Inhibitors: Do C-Terminal Interactions Play a Key Role in Their Inhibitory Activity? J. Phys. Chem. B 2016, 120, 1615-1623. [CrossRef]

156. Cramer, P.E.; Cirrito, J.R.; Wesson, D.W.; Lee, C.Y.D.; Karlo, J.C.; Zinn, A.E.; Casali, B.T.; Restivo, J.L.; Goebel, W.D.; James, M.J.; et al. ApoE-Directed Therapeutics Rapidly Clear $\beta$-Amyloid and Reverse Deficits in AD Mouse Models. Science 2012, 335, 1503-1506. [CrossRef]

157. Huy, P.D.Q.; Thai, N.Q.; Bednarikova, Z.; Phuc, L.H.; Linh, H.Q.; Gazova, Z.; Li, M.S. Bexarotene Does Not Clear Amyloid Beta Plaques but Delays Fibril Growth: Molecular Mechanisms. ACS Chem. Neurosci. 2017, 8, 1960-1969. [CrossRef]

158. Pham, H.D.Q.; Thai, N.Q.; Bednarikova, Z.; Linh, H.Q.; Gazova, Z.; Li, M.S. Bexarotene Cannot Reduce Amyloid Beta Plaques through Inhibition of Production of Amyloid Beta Peptides: In Silico and in Vitro Study. Phys. Chem. Chem. Phys. 2018, 20, 24329-24338. [CrossRef]

159. Mei, J.; Yang, H.; Sun, B.; Liu, C.; Ai, H. Small-Molecule Targeted A $\beta 42$ Aggregate Degradation: Negatively Charged Small Molecules Are More Promising than the Neutral Ones. ACS Chem. Neurosci. 2021, 12, 1197-1209. [CrossRef] [PubMed]

160. Cohen, S.I.A.; Linse, S.; Luheshi, L.M.; Hellstrand, E.; White, D.A.; Rajah, L.; Otzen, D.E.; Vendruscolo, M.; Dobson, C.M.; Knowles, T.P.J. Proliferation of Amyloid-B42 Aggregates Occurs through a Secondary Nucleation Mechanism. Proc. Natl. Acad. Sci. USA 2013, 110, 9758-9763. [CrossRef]

161. Heller, G.T.; Aprile, F.A.; Michaels, T.C.T.; Limbocker, R.; Perni, M.; Ruggeri, F.S.; Mannini, B.; Löhr, T.; Bonomi, M.; Camilloni, C.; et al. Small-Molecule Sequestration of Amyloid- $\beta$ as a Drug Discovery Strategy for Alzheimer's Disease. Sci. Adv. 2020, 6, 1-16. [CrossRef]

162. Pagano, K.; Tomaselli, S.; Molinari, H.; Ragona, L. Natural Compounds as Inhibitors of A $\beta$ Peptide Aggregation: Chemical Requirements and Molecular Mechanisms. Front. Neurosci. 2020, 14, 1-18. [CrossRef]

163. Mahmoudinobar, F.; Nilsson, B.L.; Dia, C.L. Effects of Ions and Small Compounds on the Structure of A $\beta 42$ Monomers. J. Phys. Chem. B 2021, 125, 1085-1097. [CrossRef]

164. Ritter, C.; Adrian, M.; Riek-loher, D.; Bohrmann, B.; Do, H.; Schubert, D.; Riek, R. 3D Structure of Alzheimer's Amyloid-Beta (1-42) Fibrils. Proc. Natl. Acad. Sci. USA 2005, 102, 17342-17347.

165. Boopathi, S.; Kolandaivel, P. Targeted Studies on the Interaction of Nicotine and Morin Molecules with Amyloid $\beta$-Protein. J. Mol. Model. 2014, 20, 2109. [CrossRef]

166. Boopathi, S.; Kolandaivel, P. Study on the Inter- and Intra-Peptide Salt-Bridge Mechanism of A $\beta 23-28$ Oligomer Interaction with Small Molecules: QM/MM Method. Mol. Biosyst. 2015, 11, 2031-2041. [CrossRef]

167. Aguayo, L.G.; Gonzalez-Sanmiguel, J.; Burgos, C.F.; Bascunan, D.; Fernandez-Perez, E.J.; Riffo-Lepe, N.; Boopathi, S.; FernandezPerez, A.; Bobadilla-Azocar, C.; Gonzalez, W.; et al. Gabapentin Inhibits Multiple Steps in the Amyloid Beta Toxicity Cascade. ACS Chem. Neurosci. 2020, 11, 3064-3076. [CrossRef]

168. Peters, C.; Bascuñán, D.; Burgos, C.F.; Bobadilla, C.; González-Sanmiguel, J.; Boopathi, S.; Riffo, N.; Fernández-Pérez, E.J.; Tarnok, M.E.; Aguilar, L.F.; et al. Characterization of a New Molecule Capable of Inhibiting Several Steps of the Amyloid Cascade in Alzheimer's Disease. Neurobiol. Dis. 2020, 141, 104938. [CrossRef]

169. Ciuperca, I.S.; Dumont, M.; Lakmeche, A.; Mazzocco, P.; Pujo-Menjouet, L.; Rezaei, H.; Tine, L.M. Alzheimer's Disease and Prion: An in Vitro Mathematical Model. Discret. Contin. Dyn. Syst. -Ser. B 2019, 24, 5225-5260. [CrossRef]

170. Habchi, J.; Chia, S.; Galvagnion, C.; Michaels, T.C.T.; Bellaiche, M.M.J.; Ruggeri, F.S.; Sanguanini, M.; Idini, I.; Kumita, J.R.; Sparr, E.; et al. Cholesterol Catalyses A $\beta 42$ Aggregation through a Heterogeneous Nucleation Pathway in the Presence of Lipid Membranes. Nat. Chem. 2018, 10, 673-683. [CrossRef] [PubMed]

171. Banerjee, S.; Hashemi, M.; Zagorski, K.; Lyubchenko, Y.L. Cholesterol in Membranes Facilitates Aggregation of Amyloid $\beta$ Protein at Physiologically Relevant Concentrations. ACS Chem. Neurosci. 2021, 12, 506-516. [CrossRef] [PubMed] 